\title{
The Impact of Security Trading on Corporate Restructurings*
}

\author{
Konstantinos E. Zachariadis ${ }^{\dagger} \quad$ Ioan F. Olaru ${ }^{\ddagger}$
}

Review of Finance forthcoming

\begin{abstract}
Hedge funds are heavily involved in corporate restructurings. What makes their involvement distinct from other investors is that hedge funds can trade across the securities of a firm, holding either long or short positions in each security. We analyze the choice of a restructuring proposal by a firm's manager in the presence of a hedge fund as a potential investor in the firm. We show that, under certain market conditions, there is an equilibrium where the firm's manager makes a proposal for which a hedge fund finds it profitable to short-sell the equity of the firm, buy the debt of the firm, and via its debtholdings lead the firm to a value-reducing outcome to gain on its short equity position. The necessary and sufficient market conditions under which the aforementioned equilibrium occurs are that the debt and equity markets are segregated and that other traders in the equity market are net buyers on average.
\end{abstract}

JEL Classification: G30, G32, G33, G34

Keywords: debt restructuring, short-selling, hedge funds, empty creditors, distressed investing

*This paper was circulated before under the title "Trading and Voting in Distressed Firms". We thank the Referee, and the Editor, Vikrant Vig, for insightful input. For helpful comments we thank Ulf Axelson, Bernie Black, Amil Dasgupta, Daniel Ferreira, Mike Fishman, Thierry Foucault, Christopher Hennessy, Peter Kondor, Samuel Lee, Elu von Thadden, Dimitri Vayanos and seminar participants at LSE, Toulouse, the European Winter Corporate Finance Conference 2011 and CEPR's ESSET 2011. K. E. Zachariadis gratefully acknowledges financial support from the Paul Woolley Centre at the LSE. The views expressed here are those of the authors and not necessarily those of Graham Capital Management.

${ }^{\dagger}$ Department of Finance, London School of Economics, Houghton St, London WC2A 2AE, United Kingdom, $p h$ : +442079556541, fax: +442078494647, e-mail: k.zachariadis@lse.ac.uk. (corresponding author)

${ }^{\ddagger}$ Graham Capital Management, e-mail: iolaru@grahamcapital.com. 


\section{Introduction}

Debt restructurings (or loan amendments) can prove disruptive for a firm's operations and have real effects on production and investment. Done successfully they help realize firm value, while failure to do so can prove detrimental to the firm and some - if not all - of its claimholders. In particular, the effect of trading in a firm's securities while it is undergoing a restructuring is topical given the current economic environment where many firms - and even countries - need to restructure their debt, and where issues of short-selling and trading in credit-default-swaps (CDS) are closely monitored by regulators.

In an overwhelming number of firms that underwent debt restructurings there was some involvement by hedge funds. According to Jiang, Li, and Wang (2012) hedge funds were present in 94\% of the biggest Chapter 11 (debt restructuring) filings in the United States between 1996-2007; their exposure in $79 \%$ (55\%) of the cases was in the debt (equity) of the distressed firm, while the time in which funds acquired that exposure varied between before and after the filing. ${ }^{1}$ Moreover, Massoud, Nandy, Saunders, and Song (2011) document the heavy involvement of hedge funds in the syndicated loans markets in lieu of commercial banks, and their equity short-selling activity around loan amendments. ${ }^{2}$

The rules governing restructurings rely on the assumption that claimholders' voting rights are proportional to their economic exposure to the firm's value. Economic exposure is straightforward to define for traditional financiers, such as commercial banks in the United States, which are only allowed to have long positions in the equity of their debtors (see Section 6.8 and Jiang, Li, and Shao (2010)). However, other investors, such as hedge funds and private equity funds, have the ability to employ a more diverse spectrum of strategies. In particular, in this paper, we focus on the ability of these funds to short-sell the equity of their debtors, which creates a disconnect between their voting rights as debtholders and their overall economic exposure in the firm.

The involvement of hedge funds and private equity funds (henceforth 'funds') in restructurings has been widely documented in popular press articles (Durfee (2006), Taub (2005), Sakoui (2008), and Economist Staff (2009)) and articles in law literature (Skeel and Partnoy (2006), Kahan and Rock (2007), Hu and Black (2008), and Ayotte and Morrison (2009)). The narrative provided by the aforementioned sources is the following: funds 'prey' on otherwise good companies that need to restructure their debt, obtain significant positions in their securities so that they can affect the outcome of these restructurings, and force firms into inefficient outcomes. In the words of Skeel and Partnoy (2006):

"...But one widely rumored explanation is that, in addition to their position as financiers

of Tower (Automotive), the hedge funds also had shorted its stock, that is, they bor-

\footnotetext{
${ }^{1}$ Jiang, Li, and Wang (2012) empirically explore the role of hedge funds in distressed firms. However, they do not have data on funds' short positions or CDS holdings and so their empirical predictions are not directly comparable with the theoretical results in this paper.

${ }^{2} \mathrm{~A}$ 'toehold' in a firm's loan allows a fund to affect the outcome of an amendment, but also to have material private information. The fund can exploit such information by, for example, short-selling before the public announcement of the amendment. In our setup we focus exclusively on the control channel because we want to study the consequences of a fund's involvement in loan amendments, even if a fund does not trade early on its private information.
} 
rowed Tower stock and stood to profit if the value of the stock declined. Some bankers, as the Wall Street Journal later reported, believe hedge funds triggered the (Chapter 11) filing to make their short positions worth more..." [emphasis added]

In this paper we inquire whether the strategy mentioned in the quote above can be rationalized in a setup where both the restructuring proposal as well as a fund's positions in the securities of a firm are endogenous. It is certainly not hard to construct a scenario with a fixed proposal and a fund with fixed positions where firm value is reduced and some claimholders are hurt. However, the outcome of a restructuring procedure is not straightforward once we endogenize the proposal, especially when a fund has to pay the trading price to build any positions following that proposal. In order to derive the outcome we study the strategic interaction between a firm's manager and a fund. The firm's manager is fully aligned with the firm's equityholders and suggests a restructuring proposal (a split of the available surplus between debt and equity holders) to maximize the value of equity, while foreseeing a fund's potential involvement in the firm. The fund observes the proposal and can then trade in both the firm's debt and equity (short or long). ${ }^{3}$

So when will the manager of a firm find it optimal to make a proposal that will lead a fund to buy the firm's debt, short-sell the firm's equity, and via its debtholdings force the firm into a value-reducing (i.e., inefficient) outcome? We show that this is the case when other investors' trades in the equity market are positive in expectation (but not deterministic) and the debt and equity markets are informationally segregated (i.e., there is no exchange of order flow information between the equity and debt markets). On the other hand, when others' trading is in expectation zero (or negative) or when markets are informationally integrated (i.e., there is perfect exchange of order flow information between markets), we show that there is no rejection of proposals and hence no deadweight loss to firm value from the fund's presence. ${ }^{4}$

Intuitively, our results are driven by the fact that the fund needs to camouflage its trades to make any profit off other investors and the extent to which this is possible is affected by the integration/segregation of markets and the direction of other investors' trading. Interestingly enough, however, these conditions in turn affect the manager's incentives to risk firm value so as to garner a higher payoff for equityholders, when she picks the restructuring proposal.

In practice, the debt and equity markets differ in many important aspects. Corporate bonds are usually traded over-the-counter, while corporate equity trades in a central exchange. Hotchkiss and Ronen (2002) and Downing, Underwood, and Xing (2009) showed that the debt market lags behind the equity market and so the debt market is less informationally efficient. This lagged response varies for different kinds of bonds and in different countries, and so we expect integration/segregation to also vary. Our findings highlight that informational differences between debt and equity markets have a real effect on firms' restructurings, when strategic funds are present.

In more detail, our model works as follows (Section 2). A firm is in financial distress and wishes

\footnotetext{
${ }^{3}$ Trading of distressed securities is not prohibited in most countries and even if de-listing occurs in major exchanges, trading continues in other markets (for further discussion see Section 6.8).

${ }^{4}$ The inefficient outcome also occurs when the fund has a significant pre-existing position in the firm's debt and only trades in the firm's equity as long as others' trades in the equity market are, again, positive in expectation.
} 
to restructure its debt. The restructuring proposal is a one-shot bargaining game between the manager and the debtholders. The manager represents long-term equityholders and makes a takeit-or-leave-it offer to debtholders, who decide on it, over the split of the continuation value. We assume that the continuation value is strictly higher than the value under rejection of the proposal and liquidation (the continuation and liquidation values of the firm are known). This is done, simply, to match the example of Tower in our discussion. In this sense we say that liquidation is inefficient, and postulate that the value of equity in liquidation is zero.

In the bargaining game between the manager (essentially equityholders) and debholders, if the manager knows the equity positions held by debtholders (if any), we are in a complete information game in which the manager can always find a split of the continuation value that debtholders will accept. The known equity positions of debtholders just shift the 'bargaining power' from one claimholder to the other. Hence, there is no inefficient liquidation, no deadweight loss, and no 'money left on the table'. The full information efficient outcome follows directly from the Coase Theorem of efficient bargaining (Mas-Colell, Whinston, and Green (1995, Page 357)): since all claimholders are around the bargaining table, any deadweight loss from rejection of the proposal would be internalized by them, which of course none of them is willing to consent to (Section 3).

However, the outcome may be different if there is trading after the manager's proposal but before debtholders decide to either accept or reject the proposal. It is reasonable to assume that most 'opportunistic' trade occurs after the proposal, since it is the very announcement of a restructuring that attracts the so called 'vulture funds' (Howard and Hedger (2008, sec. 6.1)). We model the market in either debt or equity à la Kyle (1985), so that trade is intermediated by competitive market-makers who receive aggregate order flows from two types of investors: a strategic fund and other traders with exogenous trades.

So the important complication is that in order to build up the relevant positions, the fund must pay for them in the market. If either the debt or the equity market-maker can infer the fund's positions from the aggregate order he observes, some - if not all — of the gains to the fund will be lost. This will in turn affect the fund's trading behavior and ultimate decision on the proposal (when it buys debt). Note that the manager's proposal and the fund's presence are common knowledge at the trading stage and so there is no ex-ante informational asymmetry between the market-makers (in debt and equity), the manager and the fund. Hence, for the fund to profit from trading in either market it has to conceal its trades. It can only do that if others' trades are random and the fund also randomizes (mixes) between its available actions in either market.

Ultimately, the manager, anticipating the fund's strategy, must choose between giving a low enough payoff to equityholders and increasing the probability of continuation, or a high payoff to equityholders while risking liquidation. We may reasonably expect that the presence of the fund, which is a (potential) debtholder and has the ability to short-sell equity, will lead to higher payoffs for debtholders, and lower payoffs for equityholders, both relative to the case where the fund was absent and we only had pure debtholders, i.e., debtholders without any equity positions. ${ }^{5}$ It is less obvious whether inefficient liquidations would arise in equilibrium.

\footnotetext{
${ }^{5}$ The ability of debtholders to short equity can thus mitigate deviations from priority (Eberhart and Weiss (1998)).
} 
Since we have two markets, one for debt and one for equity, we consider two cases regarding the exchange of information between them: segregated and integrated markets. In the case of segregated markets (Section 4) the market-maker in one market cannot condition on the aggregate flow in the other and so the fund can treat the two markets separately. The information segregation makes it a weakly dominant strategy for the fund to procure debt, as this is the only way it can affect the outcome. ${ }^{6}$ Since the fund becomes a debtholder for any proposal value, the cost of becoming so, the price of debt, can be viewed as 'sunk' when the fund decides on its equity trading. The sunken-ness of the cost of debt makes the case of segregated markets equivalent (in terms of managerial proposal, the fund's equity trading, and outcome) to the case of an existing pivotal debtholder fund that only trades in the firm's equity.

Importantly, we show that when markets are segregated there can be an equilibrium where liquidation occurs with positive probability. The necessary and sufficient condition for liquidation to occur is that other investors are in expectation (but not deterministically) long in the equity market. ${ }^{7}$ In practice, positive expected trades may occur if, for example, some market participants face binding short-selling constraints (see discussion in Section 6.8). A corollary of this result is that in the symmetric case where the expected trades of other non-strategic investors are zero, there is no liquidation. Most papers in the literature fix the expectation of others' trades to the symmetric case (a notable exception being Kyle and Vila (1991)). In our paper, the expectation of others' trades is an important parameter and leads to a different outcome (liquidation vs. continuation) depending on its value.

The intuition for the result in the case of segregated markets is as follows. For any proposal the fund is a pivotal debtholder, so it unilaterally determines the outcome (liquidation or continuation). If the manager makes a low proposal (i.e., keeps very little of the continuation surplus for equityholders) the fund will buy equity (since it is cheap) and accept the proposal, while if she makes a high proposal (so that equityholders get most of the surplus) the fund will short-sell equity (since it is expensive) and reject the proposal. Both of these trades by the fund, since they happen with probability one and hence are inferred perfectly by the market makers, lead to zero trading profits. However, for intermediate proposal values, the fund can make profit by randomizing between going long and going short equity, since the value of equity is neither too low to prevent short-selling nor too high to prevent buying. These trading profits come at the expense of other traders, since the equity market-maker always breaks even in expectation.

Now, given the fund's strategy, why would the manager ever pick a proposal that would lead to liquidation, and why would she do so only when others are long equity in expectation. Conditional on others buying equity in expectation, a short-sale by the fund is more easily camouflaged, as it leads with a higher probability to a zero aggregate order, which is the state of uncertainty for the equity market-maker. This implies that even for low proposal values (i.e., a low promised part of the continuation value to equityholders) the fund has an incentive to randomize and make trading

\footnotetext{
${ }^{6}$ In our analysis, if the fund buys debt then it becomes the pivotal debtholder, i.e., one who can unilaterally determine the outcome of the restructuring procedure by either accepting or rejecting the manager's proposal.

${ }^{7}$ Strictly speaking, we take other investors trading in equity, $z_{E}$, to be +1 with probability $\nu_{E}$ and -1 with probability $1-\nu_{E}$. What we need for liquidation is that $\nu_{E}>\sqrt{5} / 2-1 / 2 \approx 0.62$.
} 
profits. The manager anticipates this and understands that for a wide range of proposal values she risks liquidation. Her decision depends on whether the long-term equityholders of the firm will have to fully internalize the deadweight loss in the case of liquidation. Actually, this deadweight loss is now externalized in part to the other traders, in the form of trading profits for the fund, and so this allows equityholders to get more in expectation even by risking liquidation. If the fund's and equityholders' payoffs summed up to firm value then the Coase Theorem would still hold (as it does in the equilibrium with continuation). It is other traders who offer an external source of profit to the fund and this leads to an equilibrium where the Coase Theorem is violated. ${ }^{8}$

In the case of integrated markets (Section 5) where each market-maker observes the aggregate order flow of the other perfectly, the fund faces more informationally complete markets. This greatly impedes the fund's ability to camouflage its trades. Moreover, any trade in the debt market will now also affect its trade in the equity market, and vice versa, and so these decisions should be made jointly. To see this, assume that the proposal is such that a pure debtholder would accept (so that the value of debt is higher under continuation than under liquidation). Then if the fund buys equity for sure this will not only lead to a zero profit in the equity market, but will also allow the debt market-maker to infer that the fund will accept the proposal if it buys debt (so that it can affect the outcome). This will in turn increase the price of debt, and hence the cost of the overall strategy to the fund (and similarly if the proposal is such that a pure debtholder would reject). So for most proposals the fund still finds it optimal to buy debt, but it randomizes between going long and going short equity over a wider range of proposals than in the case of segregated markets. ${ }^{9}$

Market integration has as a consequence that the fund's strategy does not depend on the value of the expectation of others' trading. A further important feature of the fund's optimal strategy is that for a given proposal, if the fund trades so that it makes profit from other traders, this results in a rapid loss in firm value. In particular, in the integrated case, profit to the fund and liquidation comes with a greater loss to equityholders than in the segregated case. The strategy of the fund under market integration, in turn, pushes the manager to a 'corner solution' when she picks the restructuring proposal. The optimal proposal now is such that it would be accepted even by a debtholder fund which has shorted all the equity of its debtor: this is because it gives the least possible amount of the surplus to equityholders (and the maximum to debtholders). For this very low proposal the fund buys debt and equity, and accepts the proposal (leading the firm to continuation) with probability one. Hence, the fund in equilibrium makes zero profit, and so is indifferent between entering the market altogether or not. Therefore, it is only the fund's presence and threat of involvement that leads to a proposal by the manager that guarantees the efficient outcome (the threat is credible due to the existence of other traders). The manager cannot make a higher proposal, risk liquidation and secure more for equityholders, exactly because other traders do not offer the same 'external source of profit' in the integrated case.

\footnotetext{
${ }^{8}$ The fact that we need a certain trading behavior by other traders to get liquidation highlights that it is not trading per se that it is to blame for the inefficiency.

${ }^{9}$ Although the fund finds it optimal to buy debt for most proposal values, this is not a weakly dominant strategy as in the case of segregated markets, since buying debt in the case of integrated markets is only optimal when the fund also follows a particular mixing strategy in the equity market.
} 
As expected, regardless of the integration/segregation of markets, equityholders are hurt and debtholders benefit by the fund's presence, relative to a case with only pure debtholders. However, notice that in the presence of the fund, equityholders prefer the case of segregated markets relative to integrated markets, as they get more in expectation in the former one.

Further, in order to exhibit the generality and robustness of our main results we show how our setup can be modified to address closely related issues as well as present an extension where we endogenize others' trades (Sections 6.1-6.7). Specifically, in Section 6.1 we discuss what happens when there is trade only before the proposal. In Section 6.2 we describe the similarities and differences between a short equity position and a CDS position, in the context of our model. In Section 6.3 we consider the case where others' equity trading is $z_{E} \in\{-1,0,1\}$ all with equal probability, to claim that it is the expectation and not the variance of others' trading that matters for our results. As mentioned, liquidation and continuation are mere labels; in Section 6.4 we briefly cover the 'mirror' case that liquidation is better than continuation. In Section 6.5 we elaborate on what we mean by 'debt' in the model by contrasting corporate bonds with bank debt. Moreover, a simple relabelling of the main actors in our model allows us to replicate our analysis for merger proposals in Section 6.6. Finally, in an important extension in Section 6.7 we model other traders as a strategic opportunistic fund and endogenize their order flow; we show that this has no effect on our qualitative results regarding the occurrence of the inefficient outcome.

Our primary innovations in this paper are the following. First, we show that secondary market trading has an effect on important corporate decisions like debt restructurings. Second, we highlight that it is exactly in these restructurings - where the interplay between different claimholders is crucial - that the identity of the potential investors (e.g., hedge funds vs. commercial banks) plays an important role in determining the final outcome. The nature of our results is both positive and normative: we explain the outcome and split of surplus amongst claimholders in debt restructurings; and we offer solutions to avoid the occurrence of inefficient outcomes. For example, an implication of our results is that firms with securities that trade in integrated markets will have a higher debt capacity than those that trade in segregated markets, and so to secure more debt financing for firms we should push for the exchange of timely information between markets for different securities of the same firm. We present our empirical and policy implications in detail in Section 6.8.

Naturally, funds' involvement in distressed firms is not limited to a trading focused strategy like the one we explore in this paper. There are cases where hedge funds/private equity funds pursue a loan-to-own strategy, in which they invest only in securities that are likely to be converted to equity after a reorganisation. These so called 'fulcrum' securities are usually unsecured debt securities, although in certain cases debtor-in-possession (DIP) financing may also be converted to equity. Moreover, during the restructuring, funds may push for organizational changes like a replacement of the firm's CEO or a key personnel retention plan (KPRP). In all cases, much of hedge fund involvement is cyclical, i.e., it occurs predominantly during loose credit market conditions (Jiang, Li, and Wang (2012, p. 515 and sec. A.2)). ${ }^{10}$

\footnotetext{
${ }^{10}$ Hedge funds also take an active role in firms outside of bankruptcy. For more information see Brav, Jiang, Partnoy, and Thomas (2008), Klein and Zur (2009), Brav, Jiang, and Kim (2010) and Brav, Jiang, and Kim (2011).
} 
Related Literature. How strategic traders take actions that affect firm value is also the topic of Kyle and Vila (1991), Maug (1998), and Kahn and Winton (1998). ${ }^{11}$ A very related paper is Brav and Mathews (2011) where the authors study the issue of 'empty voting', i.e., when a hedge fund can establish separate positions in the firm's shares and votes, and show how this can actually increase efficiency in some cases. In addition, Spamann (2012) considers the issue of trading in multiple securities of a firm and 'negative voting'. The important methodological difference between our paper and those above is the existence of a second strategic player, the firm's manager, who decides optimally on the proposal and affects the fund's actions.

Goldstein and Guembel (2008) and Khanna and Mathews (2012) focus on short-selling and show how funds can use their information to manipulate the market. Moreover, Caballé and Krishnan (1994) study trading in multiple-securities in a Kyle (1985) environment. ${ }^{12}$ The main difference in our model is that trading is not driven by the fund's superior information or because it wants to manipulate the market, but because it can affect the outcome. There is empirical support (Massoud, Nandy, Saunders, and Song (2011)) that hedge funds indeed rely on superior information when they trade in the equity and/or debt of a firm. As is known, asymmetric information might lead to a hold-up in negotiations (Gul (2001) and Lau (2008)) like restructurings. In our paper we shut down this channel so that we can distill the market features that may lead to a failure in negotiations above and beyond the effect of informational asymmetries.

Another channel in which short-selling can induce asset liquidations is explored in Brunnermeier and Oehmke (2013), where a short-seller might force a highly leveraged institution to sell its longterm assets at distressed prices in order to fulfill immediate funding needs. This channel is pertinent to financial institutions, which have maturity/liquidity-mismatches, while the channel we explore in this paper is relevant for financial and non-financial institutions alike. Overall, our paper highlights another case in which short-sales may be detrimental and where a short-selling ban may be optimal (see also further discussion in Section 6.8).

Bolton and Oehmke (2011) study a firm's debt financing in the presence of 'empty creditors', who can hedge their economic exposure through the use of credit derivatives. ${ }^{13}$ They show that although overinsurance in the CDS markets increases the probability of liquidation, ${ }^{14}$ the availability of CDS deters the manager from strategic default. In terms of theme, Bolton and Oehmke (2011) and our paper are very related. However, the focus of the analysis is different. Bolton and Oehmke (2011) focus on the ex-ante design of the debt contract for a given number of debtholders, while we treat debt as a traded security so that when the fund wants to become a debtholder it needs to pay the cost (price). Importantly, in Bolton and Oehmke (2011) CDS trades lead to zero profit, but CDS

\footnotetext{
${ }^{11}$ In a recent paper Chemla and Hennessy (2014) study similar issues to Maug (1998) and Kahn and Winton (1998), but dispense with pure noise traders, thus allowing for a welfare analysis.

${ }^{12}$ Moreover, Caballé and Krishnan (1994) make the assumption of integration, so to the best of our knowledge ours is the first paper to contrast the optimal behavior of a strategic trader when market-makers observe order flows on other markets versus when they do not.

${ }^{13}$ Similar issues to Bolton and Oehmke (2011) are also studied in the theoretical work of Campello and Matta (2012). The empirical literature on empty creditors has been limited by the available data and has so far returned mixed results, see, e.g., Bedendo, Cathcart, and El-Jahel (2010) and Danis (2012).

${ }^{14}$ The rationale, as also highlighted in Yavorsky, Bauer, Gates, and Marshella (2009), is the increased negotiation power of debtholders in the presence of CDS insurance. This effect is also present in our paper.
} 
positions shift the bargaining power and in the case of overinsurance lead to liquidation (since there is no proposal that would satisfy an overinsured debtholder). In our paper, overinsurance is ruled out (since a debtholder can at most short-sell all the equity of the firm) while liquidation results from the strategic interplay between the manager and the fund.

The rest of the paper is structured as follows. Section 2 presents the model. In Section 3 we cover the benchmark case of complete information (no trading and full disclosure). Section 4 contains the case of segregated markets, while Section 5 covers the case of integrated markets. Related issues, the extension with endogenous others' trades and the implications of our model, are discussed in Section 6. Section 7 concludes. All proofs of the results in Sections 4-5 are in Appendix A and the analysis for the extension in Section 6.7 is in Appendix B.

\section{Model}

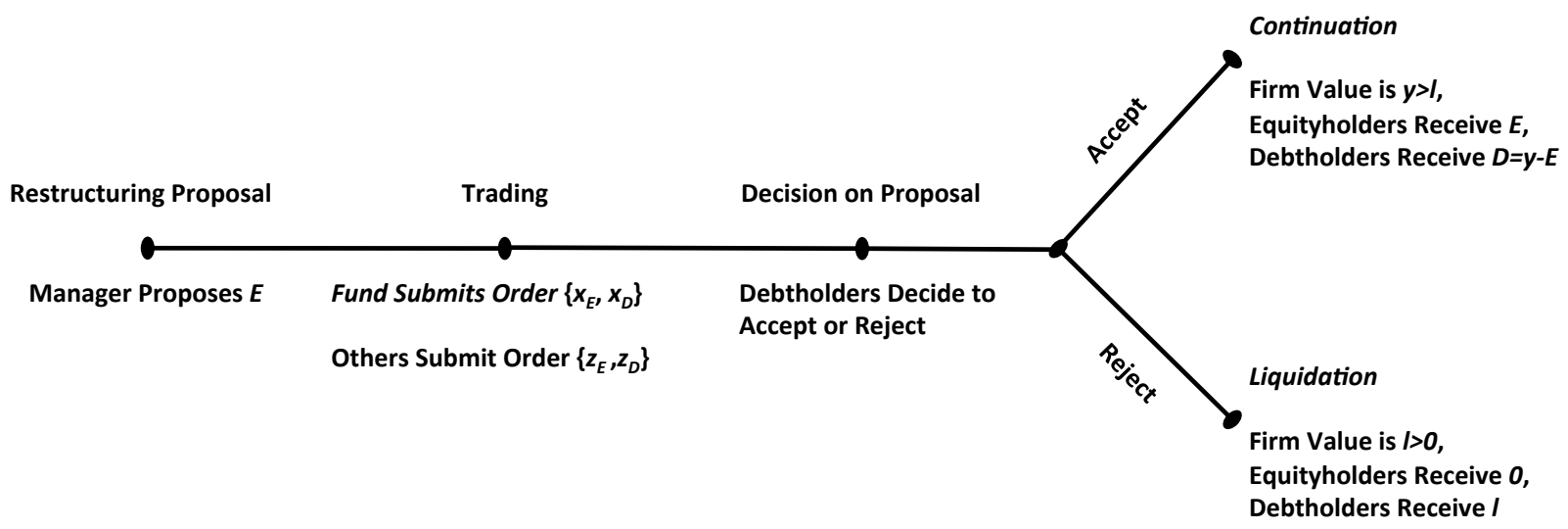

Figure 1: Model Timeline.

We consider a single firm with two tradable claims in its capital structure debt and equity. ${ }^{15}$ The firm has either defaulted outright on its debt obligations or anticipates financial hardships in the future, and so wishes to restructure its debt. The timeline, as seen in Figure 1, is as follows: first, a restructuring proposal is made, which is a split of the firm's value, conditional on acceptance of the proposal (continuation) between debt and equity holders; after the proposal there is trading in the firm's claims (debt and equity); following trading there is a decision to accept or reject the proposal; finally, the outcome that has been decided (liquidation or continuation) and the corresponding payoffs to claimholders are realized.

The expected continuation firm value $y$ is known and certain at the time of the proposal (i.e., there are no agency problems arising from the manager's private information and/or choice of effort). In the event of rejection of the proposal the firm can be thought of as liquidated with

\footnotetext{
${ }^{15}$ We are not going to distinguish between senior and junior debt, or between preferred and common shares. Debtholders are senior claimants, while equityholders are residual claimants. No short-term borrowing is allowed.
} 
(expected) value of liquidation $l$, known to all when the proposal is made. We assume that $y>l$, that is, continuation is better than liquidation from a firm value perspective. ${ }^{16}$ This allows us to call liquidation the inefficient outcome as in our motivating example about Tower Automotive. Furthermore, we postulate that the liquidation value is not enough to cover residual debt claims and so equityholders receive nothing in the event of liquidation. This last assumption is standard in the literature and in our case offers some expositional clarity. Let then

$$
E_{0} \equiv y-l,
$$

which is strictly greater than zero since $y>l ; E_{0}$ is a measure of how much more efficient continuation is than liquidation. Hence, it is the surplus over which debtholders and equityholders bargain.

There are two main strategic players in our model: the firm's manager and a single investment fund. The firm's manager chooses the restructuring proposal to maximize the expected value to the long-term equityholders of the firm, an objective which is rationalized by postulating that the manager: (i) holds some small, undiversified equity stake in the firm; (ii) has no other claims in the firm; and (iii) cannot trade or hedge her equity position in the firm during the restructuring. Essentially, the manager's assumed objective emphasizes that the outcome of the debt restructuring process depends on the conflict between claimholders. Note that our restructuring model is a particular case of Hart and Moore (1998) in which equityholders have all the bargaining power. ${ }^{17}$ The manager's proposal is equivalent to a payment to equityholders conditional on continuation, $E$, so that the promised payment to debtholders is $D \equiv y-E$. Hence, after the proposal has been made and before a decision has been reached, the equity of the firm is essentially an asset that pays $E$ in the event of continuation and zero otherwise, while the debt is an asset that pays $D$ in the event of continuation and $l$ otherwise.

The single, profit-maximizing investment fund has the following distinguishing feature from other investors: it can hold both debt and equity claims and, in particular, it can short-sell the equity of its debtor. ${ }^{18}$ We consider only discrete possible values of the fund's equity and debt positions to focus on the direction of trade rather than quantity. Hence, the final fund's positions in equity and debt can be $x_{E} \in\{-1,0,1\}$, and $x_{D} \in\{0,1\}$, respectively. The symmetry between long and short positions in equity, and the choice of one unit are normalizations that facilitate exposition. The fund has no capital constraints, and may have claims in the firm before the proposal or obtain them in the trading round following the proposal. The fund is the only strategic player to participate in the trading round. ${ }^{19}$

\footnotetext{
${ }^{16}$ This is without loss of generality in the sense that if instead $y<l$ all our results remain the same by interchanging 'continuation' with 'liquidation' (Section 6.4).

${ }^{17}$ Varying the bargaining power in favor of debtholders would make rejection of the proposal less probable in our model but would not alter our qualitative results.

${ }^{18} \mathrm{It}$ is without loss of generality that the fund does not short-sell debt since it gains nothing by doing so.

${ }^{19}$ This is of course a partial equilibrium setting where we focus on the fund's strategy in only one firm. In practice, the fund's trades will be optimized at the portfolio level. For example, it may be that a distressed fund's portfolio is comprised of firms in the same industry and so strategic business considerations across firms will play a role in the fund's involvement in each of them.
} 
Trading in each market (debt or equity) is modeled in the spirit of Kyle (1985). The equity market-maker receives aggregate order $y_{E}$ from the fund and other traders and picks the price of equity $p_{E}$ to break even in expectation. Similarly, the debt market-maker receives $y_{D}$ and picks $p_{D}$. If the equity market-maker just observes $y_{E}$ and the debt market-maker just observes $y_{D}$, then we call markets segregated. If both market-makers observe $\left\{y_{E}, y_{D}\right\}$, then we call markets integrated. Other traders' order flows in both markets are exogenous and random, independent from each other and any other variable in the model. In particular, we assume that others' equity trading is of level $z_{E} \in\{-1,1\}$ and let $\nu_{E} \equiv \mathbb{P}\left[z_{E}=1\right]$, while their debt trading is of level $z_{D} \in\{0,1\}$ and let $\nu_{D} \equiv \mathbb{P}\left[z_{D}=1\right] .{ }^{20}$ We treat $\nu_{E}, \nu_{D} \in(0,1)$ as given constants.

Both market-makers, when they set prices, and the manager, when she makes the proposal, know the existence of the fund and understand its incentives. The manager, the fund, and the market-makers are all risk neutral; the risk-free interest rate is zero.

Debtholders are the ones who decide to accept or reject the proposal after trading is over. Inside bankruptcy (Chapter 11 in the US and scheme of arrangement in the UK, or for other restructurings such as merger proposals (Section 6.6)) there is a formal vote by the debtholders so that the outcome of the vote is binding for all. ${ }^{21}$ Outside formal bankruptcy proceedings (out-ofcourt restructurings or workouts) there is no formal vote on the restructuring and debtholders have to accept or reject on an individual basis; however, bankruptcy filings (as in the case of Tower) - or even outright liquidation - can occur if not enough key debtholders agree to the plan. To abstract from the way the actual outcome is determined we will posit that if the fund decides to acquire debt (or already owns debt), that is when $x_{D}=1$, then it becomes the pivotal debtholder so that rejection or acceptance of the proposal relies solely on the fund. On the other hand, if there are only pure debtholders we view them as small and atomistic, in the sense that they judge the proposal solely based on what it pays in continuation versus what it pays in liquidation (so we also assume they are risk-neutral). Admittedly, this is a reduced form model of an actual debt restructuring procedure, in which the proposal is the result of lengthy negotiations between equity and debt holders, and the outcome may be challenged by a judge (in statutory procedures). However, our main goal here is to highlight the role of trading in the procedure. ${ }^{22}$

We solve the model for the fund's and manager's optimal strategies by backward induction and so our equilibrium concept is Subgame Perfect Nash Equilibrium. We also rule out weakly dominated strategies for the fund in the trading round and hence impose a trembling-hand refinement. ${ }^{23}$

\footnotetext{
${ }^{20}$ Hence for $\nu_{E}>1 / 2$ the expectation of others' trades in the equity market, $2 \nu_{E}-1$, is positive, and in that sense this case can be thought of as capturing binding short-selling constraints faced by some market participants.

${ }^{21}$ Usually votes corresponding to $2 / 3$ of the value of debt outstanding are needed to pass these proposals.

${ }^{22}$ For an extensive coverage of the law governing restructurings (with a UK focus) see Howard and Hedger (2008).

${ }^{23}$ The non-inclusion of weakly dominated strategies is consistent with agents' caution and not just agents' rationality (Mas-Colell, Whinston, and Green (1995, Section 8.F)).
} 


\section{Benchmark Cases}

First, we consider the benchmark case in which there is full position disclosure and no trading allowed between the proposal date and the decision date.

\subsection{Pure Debtholders}

Pure debtholders can be viewed as a single 'representative' debtholder who: accepts the proposal if and only if $D \geq l \Longleftrightarrow E \leq y-l=E_{0}$, where the last equality follows from (1); and rejects the proposal if and only if $D<l$. Hence, the maximum promised payment to equityholders, conditional on continuation, for which pure debtholders would be in favor of continuation is equal to $E_{0}$. Note that in this complete information bargaining game it is straightforward that the Nash bargaining solution is $E_{0} / 2$.

\subsection{Fund with Exogenous Positions}

Now, let the fund's positions $x_{E} \in\{-1,0,1\}$ in equity and $x_{D} \in\{0,1\}$ in debt be exogenous, known, and unchanged until the decision date. Given the fund's possible positions, its payoff conditional on continuation (i.e., by accepting the proposal) is

$$
x_{E} E+x_{D} D=x_{E} E+x_{D}(y-E),
$$

while its payoff conditional on liquidation (i.e., by rejecting the proposal) is

$$
x_{E} 0+x_{D} l=x_{D} l .
$$

The fund is pivotal for the outcome if $x_{D}=1$ and not pivotal if $x_{D}=0$. So, for a proposal $E$ by the manager, we have, concerning the fund's payoff:

- If $x_{D}=0$, the fund is not pivotal. Pure debtholders accept for $E \leq E_{0}$ in which case the fund gets $x_{E} E$, while they reject for $E>E_{0}$ in which case the fund gets 0 .

- If $x_{D}=1$, the fund is pivotal. It then accepts for

$$
x_{E} E+D \geq l \Longleftrightarrow\left(1-x_{E}\right) E \leq E_{0}
$$

and rejects otherwise. Hence, it accepts for: (i) all proposals if $x_{E}=1$; (ii) proposals such that $E \leq E_{0}$ if $x_{E}=0$; (iii) proposals such that $E \leq E_{0} / 2$ if $x_{E}=-1$.

Hence continuation occurs in the following cases:

1. $\left\{x_{E}=-1\right.$ and $\left.x_{D}=1\right\}$, for $E \leq E_{0} / 2$;

2. $\left\{x_{E} \in\{-1,0,1\}\right.$ and $\left.x_{D}=0\right\}$ or $\left\{x_{E}=0\right.$ and $\left.x_{D}=1\right\}$, for $E \leq E_{0}$;

3. $\left\{x_{E}=1\right.$ and $\left.x_{D}=1\right\}$, for all $E$. 
When the manager knows the fund's positions she proposes $E_{0} / 2$ in case $1, E_{0}$ in case 2, and $y$ (i.e., all of the continuation value) in case 3 . All these proposals achieve continuation with probability one, and hence, in this complete information case, maximize the expected value of equity, which is the manager's objective. In the fund's absence, the manager, as mentioned, guarantees continuation by proposing $E_{0}$. So, in all cases $1-3$ firm value is not affected by the fund's existence since continuation is achieved with probability one, as in the pure debtholders case. Hence,

Remark 1. In the case of complete information (full disclosure and no trading), firm value is not affected by the presence of the fund.

Furthermore, a fund that has shorted its debtor's equity benefits debtholders and hurts equityholders. The reverse is true when the fund is long the equity of its debtor since then equityholders receive the maximum possible promised payment. Remark 1 is not surprising and, as mentioned in the Introduction, it follows directly from the Coase Theorem.

However, if the manager does not observe the fund's positions when she makes the proposal (and so has probabilistic beliefs over cases 1,2, and 3, above) then we might get liquidation with positive probability. We examine this in the next two sections.

\section{$4 \quad$ Segregated Markets}

We now begin our derivation of the equilibrium outcome of the restructuring procedure when the fund can trade, both in the debt and the equity of the firm, after the proposal but before the decision date. In this section we cover the case of segregated markets where each market-maker just observes the aggregate order in his own market and has no information concerning the other market's aggregate order.

We start by analyzing the fund's optimal trades and decision (if it buys debt) on a given manager's proposal $E \in[0, y]$. It is assumed that the fund has no initial positions in either debt or equity. First note that for proposal $E \in\left[0, E_{0} / 2\right]$ there is always continuation since, even if the fund is pivotal and it short-sells equity, it still prefers for the firm to continue. In this case the price of equity, $p_{E}$, and debt, $p_{D}$, are equal to $E$ and $D=y-E$, respectively. The fund is then indifferent between trading or not (in either market) since its profit is always zero. Now, for $E \in\left(E_{0} / 2, E_{0}\right]$ the fund's payoff for each possible trading position $x_{E} \in\{-1,0,1\}$ and $x_{D} \in\{0,1\}$ is

$$
\Pi_{C}^{\mathrm{Seg}}\left(x_{E}, x_{D} ; E\right)=\left\{\begin{array}{cc}
\max \{E+D, l\}-\mathbb{E}\left[p_{E} \mid x_{E}=1\right]-\mathbb{E}\left[p_{D} \mid x_{D}=1\right], & x_{E}=1, x_{D}=1, \\
E-\mathbb{E}\left[p_{E} \mid x_{E}=1\right], & x_{E}=1, x_{D}=0, \\
\max \{D, l\}-E-\mathbb{E}\left[p_{D} \mid x_{D}=1\right], & x_{E}=0, x_{D}=1, \\
0, & x_{E}=0, x_{D}=0, \\
\max \{-E+D, l\}+\mathbb{E}\left[p_{E} \mid x_{E}=-1\right]-\mathbb{E}\left[p_{D} \mid x_{D}=1\right], & x_{E}=-1, x_{D}=1, \\
-E+\mathbb{E}\left[p_{E} \mid x_{E}=-1\right], & x_{E}=-1, x_{D}=0 .
\end{array}\right.
$$

The 'max' operators above signify the decision of the fund to accept or reject the proposal, which 
is relevant when it buys debt and is pivotal $x_{D}=1$. When $x_{D}=0$ pure debtholders decide the outcome: as before, for $E<E_{0}$ they accept the proposal, and lead the firm to continuation; this is what the subscript $C$ in $\Pi_{C}^{\mathrm{Seg}}$ signifies. Moreover, the expectations over the price of equity $p_{E}$, and the price of debt $p_{D}$, capture the fact that the fund does not know the aggregate demand in equity or debt when it places its order. Using the definition of $E_{0}$ from (1), that $D=y-E$ and that $y>l$ we have:

$$
\Pi_{C}^{\mathrm{Seg}}\left(x_{E}, x_{D} ; E\right)=\left\{\begin{array}{cc}
y-\mathbb{E}\left[p_{E} \mid x_{E}=1\right]-\mathbb{E}\left[p_{D} \mid x_{D}=1\right], & x_{E}=1, x_{D}=1, \\
E-\mathbb{E}\left[p_{E} \mid x_{E}=1\right], & x_{E}=1, x_{D}=0, \\
y-E-\mathbb{E}\left[p_{D} \mid x_{D}=1\right], & x_{E}=0, x_{D}=1, \\
0, & x_{E}=0, x_{D}=0, \\
l+\mathbb{E}\left[p_{E} \mid x_{E}=-1\right]-\mathbb{E}\left[p_{D} \mid x_{D}=1\right], & x_{E}=-1, x_{D}=1, \\
-E+\mathbb{E}\left[p_{E} \mid x_{E}=-1\right], & x_{E}=-1, x_{D}=0 .
\end{array}\right.
$$

Similarly, for proposals $E \in\left(E_{0}, y\right]$, the fund's payoff is

$$
\Pi_{L}^{\mathrm{Seg}}\left(x_{E}, x_{D} ; E\right)=\left\{\begin{array}{cc}
y-\mathbb{E}\left[p_{E} \mid x_{E}=1\right]-\mathbb{E}\left[p_{D} \mid x_{D}=1\right], & x_{E}=1, x_{D}=1, \\
-\mathbb{E}\left[p_{E} \mid x_{E}=1\right], & x_{E}=1, x_{D}=0, \\
l-\mathbb{E}\left[p_{D} \mid x_{D}=1\right], & x_{E}=0, x_{D}=1, \\
0, & x_{E}=0, x_{D}=0, \\
l+\mathbb{E}\left[p_{E} \mid x_{E}=-1\right]-\mathbb{E}\left[p_{D} \mid x_{D}=1\right], & x_{E}=-1, x_{D}=1, \\
\mathbb{E}\left[p_{E} \mid x_{E}=-1\right], & x_{E}=-1, x_{D}=0,
\end{array}\right.
$$

where $L$ in $\Pi_{L}^{\text {Seg }}$ signifies that for this regime of proposals a pure debtholder would reject the proposal, and lead the firm to liquidation.

Let $\preceq$ denote weak dominance, so that if we write $A \preceq B$ then strategy $A$ is weakly dominated by strategy $B$. The following result allows us to greatly simplify the fund's payoff by the exclusion of weakly dominated strategies.

Lemma 1. We have

(i) For $E \in\left(E_{0} / 2, E_{0}\right]$

$$
\begin{aligned}
\left\{x_{E}=-1, x_{D}=0\right\} \preceq\left\{x_{E}=0, x_{D}=0\right\} \preceq\left\{x_{E}=1, x_{D}=0\right\} \preceq\left\{x_{E}=1, x_{D}=1\right\}, \quad \text { and } \\
\left\{x_{E}=0, x_{D}=1\right\} \preceq\left\{x_{E}=1, x_{D}=1\right\} .
\end{aligned}
$$

(ii) For $E \in\left(E_{0}, y\right]$

$$
\begin{array}{r}
\left\{x_{E}=1, x_{D}=0\right\} \preceq\left\{x_{E}=0, x_{D}=0\right\} \preceq\left\{x_{E}=-1, x_{D}=0\right\} \preceq\left\{x_{E}=-1, x_{D}=1\right\}, \quad \text { and } \\
\left\{x_{E}=0, x_{D}=1\right\} \preceq\left\{x_{E}=-1, x_{D}=1\right\} .
\end{array}
$$


Given Lemma 1 the only two actions that survive for the whole range of proposals are $\left\{x_{E}=\right.$ $\left.1, x_{D}=1\right\}$ and $\left\{x_{E}=-1, x_{D}=1\right\}$. The fund is pivotal $x_{D}=1$ irrespective of its long or short equity position and so the pure debtholders' behavior is irrelevant and we need not distinguish between $\Pi_{C}^{\mathrm{Seg}}$ and $\Pi_{L}^{\mathrm{Seg}}$. For $E \in\left(E_{0} / 2, y\right]$ we write

$$
\Pi^{\mathrm{Seg}}\left(x_{E} ; E\right)=\left\{\begin{array}{cc}
y-\mathbb{E}\left[p_{E} \mid x_{E}=1\right]-\mathbb{E}\left[p_{D} \mid x_{D}=1\right], \quad x_{E}=1, x_{D}=1, \\
l+\mathbb{E}\left[p_{E} \mid x_{E}=-1\right]-\mathbb{E}\left[p_{D} \mid x_{D}=1\right], \quad x_{E}=-1, x_{D}=1
\end{array}\right.
$$

So why does the fund prefer to become pivotal for any proposal and no matter the price of equity $p_{E}$ or debt $p_{D}$, as well as trade in the equity of the firm (either long or short). The intuition is that when the fund has no underlying position it will trade in the firm's securities only if it can make a trading profit in either market. Moreover, since the fund has no prior information, in order to make any profit it should be able to affect the restructuring outcome and hence needs to buy debt. For this weak dominance result to hold it is crucial that the fund's debt position does not affect the price of equity and vice versa, which is true in segregated markets. Importantly, the price of becoming pivotal that enters the fund's calculations, $\mathbb{E}\left[p_{D} \mid x_{D}=1\right]$, is the same, regardless of whether the fund decides to go long or short equity and so it can be viewed as a 'sunk-cost' when the fund decides on its equity trade. Given this we have the following equivalence.

Remark 2. The equilibrium (equity trading and decision over the proposal by the fund, and the proposal by the manager) in the case of segregated markets is the same as in a case with a preexisting pivotal debtholder fund that only trades in the equity of the firm following the proposal.

To proceed with our equilibrium calculation we need to specify the derivation of the prices $p_{E}$ and $p_{D}$ by the corresponding market-makers. Each market-maker receives orders from the fund $x$ and other traders $z$ and picks prices to break even in expectation. In segregated markets, the equity market-maker observes only $y_{E} \equiv x_{E}+z_{E}$ and the debt market-maker observes only $y_{D} \equiv x_{D}+z_{D}$, and set prices for equity and debt according to the following equations:

$$
\begin{aligned}
p_{E} & =\mathbb{E}\left[\mathbb{I}(\text { continuation }) E \mid y_{E}\right]=\mathbb{P}\left[\text { continuation } \mid y_{E}\right] E \\
p_{D} & \left.=\mathbb{E}\left[\mathbb{I}(\text { continuation })(y-E) \mid y_{D}\right]+\mathbb{E}[\mathbb{I} \text { (liquidation }) l \mid y_{D}\right] \\
& =\mathbb{P}\left[\text { continuation } \mid y_{D}\right](y-E)+\mathbb{P}\left[\text { liquidation } \mid y_{D}\right] l
\end{aligned}
$$

where $\mathbb{I}(\cdot)$ is the indicator function. Both market-makers know that liquidation happens only when the fund follows strategy $\left\{x_{E}=-1, x_{D}=1\right\}$, and continuation when it follows $\left\{x_{E}=1, x_{D}=1\right\}$. However, since each market-maker only observes their own order flow they have different information on which to base their assessment of the probability of the outcome. The debt market-maker understands that the fund will become pivotal regardless of its equity trading and sets

$$
p_{D}=\lambda_{E}(y-E)+\left(1-\lambda_{E}\right) l=l+\lambda_{E}\left(E_{0}-E\right)
$$


for all values of aggregate demand $y_{D} ;{ }^{24}$ in the second equality above we use the definition of $E_{0}$ from (1). We also define

$$
\lambda_{E} \equiv \mathbb{P}\left[x_{E}=1\right],
$$

as the probability that the fund goes long (buys) in the equity market. Also note how the probability that others buy debt $\nu_{D}$ drops out from the calculation of $p_{D}$, as others' trades in the debt market are immaterial.

On the other hand the equity market-maker sets

$$
p_{E}=\left\{\begin{array}{cc}
E, & y_{E}=2 \\
\frac{\left(1-\nu_{E}\right) \lambda_{E}}{\left(1-\nu_{E}\right) \lambda_{E}+\nu_{E}\left(1-\lambda_{E}\right)} E, & y_{E}=0 \\
0, & y_{E}=-2
\end{array}\right.
$$

As is common in these trading models for $y_{E} \in\{-2,2\}$ there is full revelation of the fund's equity trade and the fund makes no profit. The fund 'camouflages' its trades only when other traders take the opposite side of the market, i.e., when the aggregate flow $y_{E}$ is zero, in which case the price is given by (3). Observe, however, that conditional on $\left\{y_{E}=0\right\}$ pricing, and hence also the fund's trading gains, depend on the probability of other traders going long in the equity market $\nu_{E}$. For example, consider the case where the fund buys with $\lambda_{E} \in(0,1)$ (so short-sells with $\left.1-\lambda_{E}\right)$. Then when the fund happens to short-sell, it ends up in state $\left\{y_{E}=0\right\}$ with probability $\nu_{E}$. Conditional on being there, the fund's trading profit in the equity market (recall that the fund rejects the proposal when it short-sells) is

$$
\frac{\left(1-\nu_{E}\right) \lambda_{E}}{\left(1-\nu_{E}\right) \lambda_{E}+\nu_{E}\left(1-\lambda_{E}\right)} E
$$

Hence, although the probability of making a trading profit in the case of a short-sale increases in $\nu_{E}$, the trading profit conditional on a short-sale decreases in $\nu_{E}{ }^{25}$

Now, since the fund finds it weakly dominant to buy debt and become pivotal it can unilaterally decide on the outcome. The decision on whether to go long or short equity (no trade is weakly dominated) is solely based on the fund's trading profits in the equity market and it will depend: on the proposed $E$; the direction of others' trading in the equity market $\nu_{E}$; and how the fund's own actions, summarized by $\lambda_{E}$, affect the price. The following proposition presents the result.

Proposition 1. In the case of segregated markets the fund's equity trading behavior varies as follows with the value of the proposal E:

(i) For $E \in\left[0, E_{0} / 2\right]$, the fund is indifferent, $\lambda_{E} \in(0,1)$; continuation occurs with probability one.

\footnotetext{
${ }^{24}$ Even for the off-equilibrium aggregate order $\left\{y_{D}=0\right\}$. 25

$$
\text { That is, } \frac{\partial}{\partial \nu_{E}}\left(\frac{\left(1-\nu_{E}\right) \lambda_{E}}{\left(1-\nu_{E}\right) \lambda_{E}+\nu_{E}\left(1-\lambda_{E}\right)} E\right)=-\frac{\lambda_{E}\left(1-\lambda_{E}\right) E}{\left[\left(1-\nu_{E}\right) \lambda_{E}+\nu_{E}\left(1-\lambda_{E}\right)\right]^{2}}<0 \text {. }
$$

In the limit case when others' trading is deterministically long, $\nu_{E}=1$, the fund's trading profits are zero.
} 
(ii) For $E \in\left(E_{0} / 2, E_{0} /\left(1+\nu_{E}\right)\right]$, it buys, $\lambda_{E}=1$; continuation occurs with probability one.

(iii) For $E \in\left(E_{0} /\left(1+\nu_{E}\right), \min \left\{E_{0} / \nu_{E}, y\right\}\right)$, it randomizes (mixes),

$$
\lambda_{E}=\nu_{E} \frac{E_{0} / E-\nu_{E}}{E_{0} / E\left(2 \nu_{E}-1\right)-\left(2 \nu_{E}^{2}-1\right)}
$$

continuation occurs with probability $\lambda_{E} \in(0,1)$.

(iv) For $E \in\left[\min \left\{E_{0} / \nu_{E}, y\right\}, y\right]$, it short-sells, $\lambda_{E}=0$; continuation occurs with probability zero.

For low proposals, the region in case (i) of Proposition 1, debtholders receive the maximum they possibly can, the fund accepts the proposal no matter what its underlying equity position is and so it is indifferent between going long or short equity. For intermediate low proposals, the region of case (ii), debtholders receive most of the surplus, the price of equity is not significant, short-selling gains would be low, hence the fund is only willing to buy equity and accepts the proposals, leading the firm to continuation. Conversely, for high proposals, the region of case (iv), debtholders receive little of the surplus, the cost of equity is high and the fund short-sells (and rejects the proposal, leading the firm to liquidation), since buying would be too expensive.

In cases (ii) and (iv) the fund plays a pure strategy in the equity market $\left(\lambda_{E}=1\right.$ and $\lambda_{E}=0$, respectively) and therefore the fund's equity trading (and consequently also debt trading) in both cases is a 'wash' and, in terms of payoff, the fund makes zero. However, the fund accepts the proposal (with probability one) in case (ii) and liquidation (with probability one) in (iv) for a smaller region of proposals than a pure debtholder would (since $E_{0}>E_{0} /\left(1+\nu_{E}\right)$ and $E_{0}<\min \left\{E_{0} / \nu_{E}, y\right\}$ ). Note the dependence of the regions on the value of the probability of others going long $\nu_{E}$. As mentioned the fund, even when it mixes, only makes trading profits in the equity market when its trade is camouflaged by others' trading (i.e., when $y_{E}=0$ ). Hence, it is not surprising that the region of case (ii) (where the fund goes long equity) shrinks with $\nu_{E}$, while the one of region (iv) (where the fund short-sells equity) expands.

For high intermediate proposals, the region of case (iii), the fund finds it profitable to mix, with probability of going long given by (4). So why would the fund reject with positive probability a proposal that pure debtholders would accept, or accept a proposal that other pure debtholders would reject. The answer lies in the possibility for positive trading profits. For $E<E_{0}$ the fund is 'expected' to accept the proposal, the value of equity is high and hence the fund can profit by shorting and rejecting the proposal; while for $E>E_{0}$ the fund is 'expected' to reject the proposal and hence the fund can profit by going long and accepting the proposal. ${ }^{26}$ To take advantage of this profit opportunity the fund will mix. The equity market-maker knows this and updates her beliefs rationally, but the extent to which she undercuts all profits that the fund can make is determined by the direction of others' trading. It is that direction, measured by $\nu_{E}$, that determines the region on which the fund exactly finds it optimal to mix its equity trading.

\footnotetext{
${ }^{26}$ The proposal values in the region of case (iii) are neither too low to prohibit short-selling nor too high to prohibit buying.
} 
Besides the region, also the mixing probability (4) in case (iii) depends on $\nu_{E}$ in a non-monotonic way. This non-monotonicity captures the fact that trading profits increase with $\nu_{E}$ when the fund goes long, and decrease when it short-sells. For the fund to randomize, the profits from these two actions should be equal. For a fixed $\nu_{E}$, for higher proposal values (so for more promised value to equityholders) the probability that the fund will go long $\lambda_{E}$ drops, since equity becomes more expensive. Most importantly, in the region of case (iii) we get liquidation with positive probability (i.e., whenever the fund short-sells).

The manager anticipates the fund's strategy and picks proposal $E \in\left[E_{0} /\left(1+\nu_{E}\right), \min \left\{E_{0} / \nu_{E}, y\right\}\right]$, to maximize the long-term equityholders' expected payoff. Since equityholders receive nothing in the event of liquidation, the equityholders' expected payoff is simply the proposal value $E$ times the probability of continuation, which is the fund's probability of going long, that for $E \in\left[E_{0} /\left(1+\nu_{E}\right), \min \left\{E_{0} / \nu_{E}, y\right\}\right]$ is given by $(4),{ }^{27}$

$$
J(E) \equiv \nu_{E} \frac{\frac{E_{0}}{E}-\nu_{E}}{\frac{E_{0}}{E}\left(2 \nu_{E}-1\right)-\left(2 \nu_{E}^{2}-1\right)} E .
$$

The above expression attains a maximum since we are maximizing a continuous, bounded function over a compact interval (Weierstrass Theorem). The question is whether the manager will ever pick $E>E_{0} /\left(1+\nu_{E}\right)$ and risk liquidation, and if so whether $E \geq E_{0}$, so that the proposal exceeds the one in the pure debtholders case. The answers to these questions and their consequences for claimholders' expected payoffs, as well as the probability of continuation, and hence firm value, are given by the following proposition, which describes the manager's equilibrium behavior.

Proposition 2. Given that the fund follows the strategy profile prescribed by Proposition 1 the manager's equilibrium proposal for segregated markets is as follows, depending on the value of $\nu_{E}$ :

(i) For $0<\nu_{E}<\underline{\nu_{E}} \equiv \sqrt{5} / 2-1 / 2$, the manager picks

$$
E=E_{0} /\left(1+\nu_{E}\right) \in\left(E_{0} / 2, E_{0}\right),
$$

with

$$
J\left(E_{0} /\left(1+\nu_{E}\right)\right)=E_{0} /\left(1+\nu_{E}\right) \in\left(E_{0} / 2, E_{0}\right),
$$

and probability of continuation equal to one.

(ii) For $\underline{\nu_{E}} \leq \nu_{E}<1$, she picks

$$
E=E_{1} \equiv\left\{\begin{array}{cc}
\frac{1-2 \nu_{E}+\sqrt{3-1 / \nu_{E}-2 \nu_{E}}}{1-2 \nu_{E}^{2}} E_{0}, & \text { for } \nu_{E} \neq 1 / \sqrt{2} \\
E_{0} / \sqrt{2}, & \text { for } \nu_{E}=1 / \sqrt{2}
\end{array} \in\left(E_{0} /\left(1+\nu_{E}\right), E_{0}\right) \subset\left(E_{0} / 2, E_{0}\right),\right.
$$

\footnotetext{
${ }^{27}$ Note that the fund's mixing probability (4) is continuous: for $E=E_{0} /\left(1+\nu_{E}\right)$ it is equal to one, while for $E=E_{0} / \nu_{E}$ it is equal to zero.
} 
with

$$
J\left(E_{1}\right)=\frac{\nu_{E}}{1+2 \nu_{E}\left(\nu_{E}-1+\sqrt{3-1 / \nu_{E}-2 \nu_{E}}\right)} E_{0} \in\left(E_{0} /\left(1+\nu_{E}\right), E_{0}\right) \subset\left(E_{0} / 2, E_{0}\right),
$$

and probability of continuation

$$
\lambda_{E}^{*} \equiv \frac{\nu_{E}}{2 \nu_{E}-1+\sqrt{3-1 / \nu_{E}-2 \nu_{E}}} \in(0,1)
$$

Given Proposition 2 we derive the expected payoff of debtholders and the fund as well as the expected firm value, all in equilibrium. To calculate the fund's expected payoff we substitute for the equilibrium proposal and equilibrium mixing probability into $\Pi^{\text {Seg }}$ using: (i) equation (10) (see proof of Proposition 2 in Appendix A) for $\mathbb{E}\left[p_{E} \mid x_{E}=1\right]$ and (ii) equation (2) for $\mathbb{E}\left[p_{D} \mid x_{D}=1\right]=p_{D}$.

Corollary 1. We have that:

(i) For $0<\nu_{E}<\underline{\nu_{E}}=\sqrt{5} / 2-1 / 2$ the debtholders' payoff is $y-E_{0} /\left(1+\nu_{E}\right) \in\left(y-E_{0}, y-E_{0} / 2\right)$, the fund's payoff is zero, and firm value is $y$.

(ii) For $\underline{\nu_{E}} \leq \nu_{E}<1$ the debtholders' payoff is

$$
y-\left(1-\lambda_{E}{ }^{*}\right) E_{0}-J\left(E_{1}\right) \in\left(y-E_{0}, y-E_{0} / 2\right),{ }^{28}
$$

the fund's payoff is

$$
\left(1-\lambda_{E}^{*}\right) E_{0}-E_{1} \nu_{E}-E_{1} \lambda_{E}^{*}\left[\frac{\left(1-\nu_{E}\right)^{2}}{\left(1-\nu_{E}\right) \lambda_{E}^{*}+\nu_{E}\left(1-\lambda_{E}^{*}\right)}-1\right],
$$

and firm value is

$$
\lambda_{E}^{*} y+\left(1-\lambda_{E}^{*}\right) l .
$$

The terms $E_{1}$ and $\lambda_{E}{ }^{*}$ are given by (6) and (8) in Proposition 2.

So, for any value of $\nu_{E}$ the optimal proposal made by the manager is below the proposal in the pure debtholders' case $E_{0}$ (see Section 3.1 ) but above the minimal proposal $E_{0} / 2$, i.e., the proposal that a pivotal fund would accept even if it was short the equity of the firm (see Section 3.2). Similarly, equityholders' payoff is above their minimal payoff (corresponding to the minimal proposal) but below their payoff in the pure debtholders case. Conversely, debtholders' payoff is above their pure debtholders payoff but below their maximal payoff (corresponding to the minimal

\footnotetext{
${ }^{28}$ To see this note that $\lambda_{E}{ }^{*} E_{0}>J\left(E_{1}\right) \Longleftrightarrow y-\left(1-\lambda_{E}{ }^{*}\right) E_{0}-J\left(E_{1}\right)>y-E_{0} ;$ and, $J\left(E_{1}\right)>E_{0} /\left(1+\nu_{E}\right)>$ $E_{0} / 2 \Longleftrightarrow y-\left(1-\lambda_{E}{ }^{*}\right) E_{0}-J\left(E_{1}\right)<y-E_{0} / 2$.
} 
proposal). Hence, the fund's presence hurts equityholders and benefits dedtholders relative to the pure debtholders case. ${ }^{29}$

The fund, given the equilibrium proposal of the manager, trades as follows. For $\nu_{E}<\underline{\nu_{E}}$ the manager makes a proposal at the end-point of the region of case (ii) of Proposition 1. Hence, the fund buys both debt and equity, accepts the proposal and the probability of continuation is one. Since this is a pure strategy the fund makes zero profits. In contrast, for $\nu_{E}>\underline{\nu_{E}}$ the manager's optimal proposal is in the region of case (iii) of Proposition 1. So the fund buys debt and mixes between going long or going short equity: when it is long it accepts the proposal, and when it is short it rejects it, and so in this region of $\nu_{E}$ we have a positive probability of liquidation. This mixing leads to a positive payoff from trading in equity for the fund.

It is the combination of the manager's incentives, the fund's trading activity and other traders' presence that may lead to liquidation. In particular, the occurrence of the inefficient outcome relies on other traders submitting positive trades in expectation (but not deterministically). Related to this we want to single out two cases in which there is no harm to firm value. First, is the symmetric case, where expected trades of others are zero. Second, is the deterministic case in which other traders' activity is known, and all the potential trading profits by the fund are undercut by the market-maker. This latter case is isomorphic to a model without other traders, and stresses the fact that it is not trading per se that it is to 'blame' for inefficient liquidations.

Remark 3. When others' trading in the equity market is symmetric (zero in expectation) $\nu_{E}=1 / 2$ or deterministic $\nu_{E} \in\{0,1\}$, firm value is maintained in equilibrium, even when markets are segregated and the fund needs to trade in both the debt and the equity of the firm.

Three features of the equilibrium described by Proposition 2 merit our attention. First, why the manager risks liquidation at all for $\nu_{E}>\underline{\nu_{E}}$. Neither manager nor the fund would be willing to take a deadweight loss action if the cost of this action was fully born by either of them. Without other traders any profit for the fund should come at the expense of the equityholders/manager. So the key to the manager's choice is that the cost of liquidation is 'externalized' to other traders. This breakdown in the Coase Theorem happens not due to any asymmetric information between the fund and the manager (or the market-maker), but because of the exogenous source of profits provided by other traders to the fund. ${ }^{30}$

Second, regardless of $\nu_{E}$, why the manager never makes a proposal higher than $E_{0}$. This is particularly surprising for $\nu_{E}>\underline{\nu_{E}}$ because one would expect the manager to risk liquidation only if she could make a higher proposal than in the pure debtholders case, especially since the fund randomizes in the region $\left(E_{0} /\left(1+\nu_{E}\right), \min \left\{E_{0} / \nu_{E}, y\right\}\right)$, which includes $E_{0}$. The answer lies in the following observation: as $E$ increases, the trading profits of the fund come with a greater increase in the expected deadweight loss from potential liquidation; hence, the net gain to manager and fund from risking liquidation at the expense of other traders is shrinking.

\footnotetext{
${ }^{29}$ Note, however, that since equityholders' (expected) payoff is always greater than $E_{0} / 2$ they prefer the uncertainty imposed by the fund's (potential) trading to the situation that the manager knows with certainty that the fund is short the equity of the firm and is a pivotal debtholder.

${ }^{30}$ Recall that this never occurred under the full information case, see Remark 1.
} 
Third, why liquidation occurs (with probability, $1-\lambda_{E}{ }^{*}>0$ ) only when $\nu_{E}>\underline{\nu_{E}}$. The reason is again that for small $\nu_{E}$ the expected deadweight loss from risking liquidation outweighs the trading profit the fund can make off other traders. More specifically, for small $\nu_{E}$ the highest proposal that is accepted with certainty (i.e., $E_{0} /\left(1+\nu_{E}\right)$, see Proposition 1$)$ is already high, which entices the fund to short-sell. Of course the smaller the $\nu_{E}$ the harder it is for the fund to 'hide' if it decides to short-sell and hence the less its trading profits. On the other hand its decision to reject the proposal after it short-sells (and hence the deadweight loss of liquidation) does not depend on whether it was detected or not in the trading round.

To visualize some of this intuition we plot in Figure 2 the equityholders' expected payoff, the fund's expected payoff, and the firm's expected deadweight loss all versus the manager's proposal $E \in\left[E_{0} / 2, y\right]$ (for $E_{0}=1$ and $l=0.1$ ). ${ }^{31}$ In the left panel we pick $\nu_{E}=1 / 3$ and in the right panel we pick $\nu_{E}=3 / 4$. In both panels we see that the fund makes trading profits in the equity market and that may lead to inefficient liquidations, which is related to our first point above. More importantly, regardless of the value of $\nu_{E}$, as $E$ increases the fund's trading profits come at a much greater loss in firm value. Actually for $E \geq E_{0}=1$ (rightmost dotted vertical line in both panels) the deadweight loss becomes even more than the equityholders' expected payoff. ${ }^{32}$ Hence, the manager would not pick a proposal $E \geq E_{0}$, in accordance with our second point above.

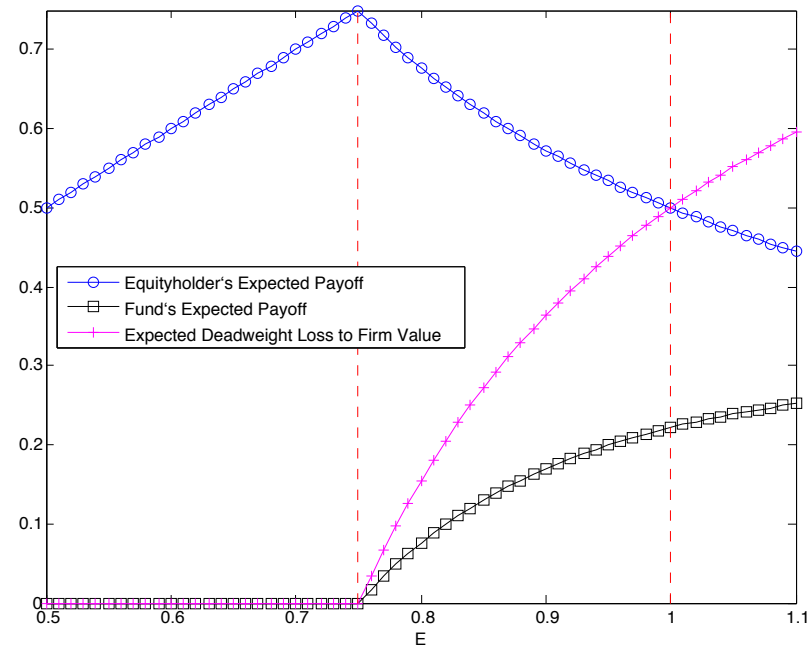

(a) $\nu_{E}=1 / 3$

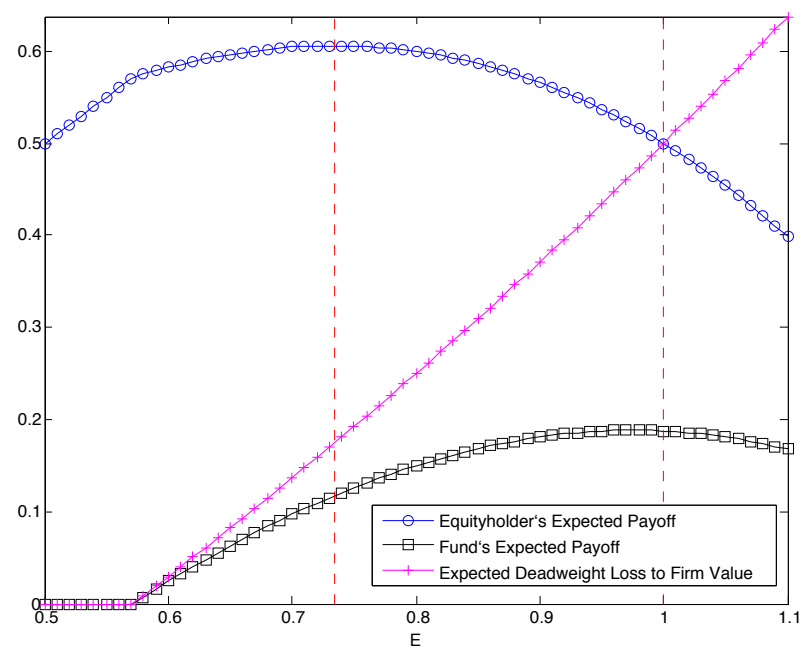

(b) $\nu_{E}=3 / 4$

Figure 2: Numerical illustration of the expected payoffs to the equityholders and the fund, as well as the expected deadweight loss to firm value vs. the manager's proposal $E \in\left[E_{0} / 2, y\right]$, for $\nu_{E}=1 / 3$ in the left panel and $\nu_{E}=3 / 4$ in the right panel $\left(E_{0}=1\right.$ and $\left.l=0.1\right)$.

Now, regarding our third point, in Figure 3 we superimpose the fund's expected payoff in the case $\nu_{E}=1 / 3$ from panel (a) of Figure 2 with the payoff in the case $\nu_{E}=3 / 4$ from panel (b) of Figure 2. In Figure 3 the leftmost dotted vertical line corresponds to the equilibrium proposal in

\footnotetext{
${ }^{31}$ The firm's expected deadweight loss is the continuation value $y$ minus the expected firm value, as given in Corollary 1.

${ }^{32}$ This can be proven using the derived expressions but we skip the proof for brevity.
} 
the case $\nu_{E}=3 / 4, E=E_{1}=0.734$. The middle one is the equilibrium proposal for $\nu_{E}=1 / 3$, $E=E_{0} /\left(1+\nu_{E}\right)=0.75$, and the rightmost corresponds to $E_{0}=1$. We see how for higher values of $\nu_{E}$ the fund is enticed to mix earlier and make trading profits (which cause a deadweight loss to firm value). This is why for $\nu_{E}=3 / 4>\underline{\nu_{E}}$ the manager picks $E=E_{1}=0.734$ (leftmost vertical dotted line in panel (b) of Figure 2) and risks liquidation, while for $\nu_{E}=1 / 3<\underline{\nu_{E}}$ she picks $E=E_{0} /\left(1+\nu_{E}\right)=0.75$ (leftmost vertical dotted line in panel (a) of Figure 2) and we get continuation for sure (see Proposition 2).

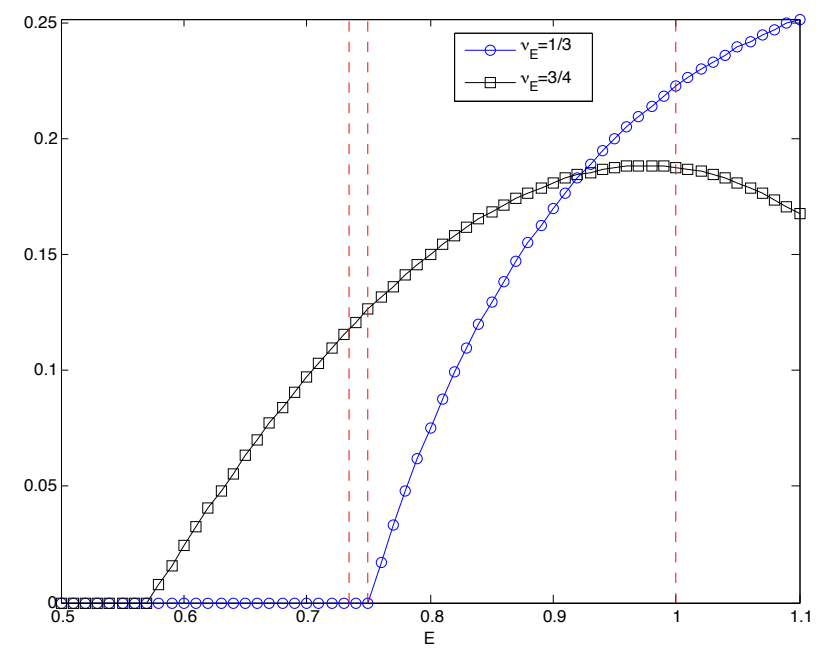

Figure 3: Numerical illustration of the fund's expected payoff vs. the manager's proposal $E \in$ $\left[E_{0} / 2, y\right]$ for two different values of $\nu_{E}\left(E_{0}=1\right.$ and $\left.l=0.1\right)$.

Finally, in Figure 4 we depict several equilibrium quantities versus $\nu_{E} \in(0,1)$ (for $E_{0}=1$ and $l=0.1$ ). In the left panel we plot the manager's proposal and the probability of continuation, which is also the probability of the fund going long, as given by Proposition 2. In the right panel we plot the expected payoffs of equityholders, debtholders, and the fund as well as the firm value, all given by the expressions in Corollary $1 .^{33}$ Of course, the sum of debtholders' and equityholders' payoffs is equal to firm value. Observe that the fund always makes a non-negative payoff since it trades only when there is a profitable opportunity.

\section{$5 \quad$ Integrated Markets}

In the case of integrated markets, in this section, an aggregate order in one market is perfectly observed from the other, and vice versa. This creates a more informationally complete environment in which the fund contemplates trading in order to maximize its profit. Let us begin with the derivation of the fund's best response given managerial proposal $E .^{34}$ For proposals $E \in\left(E_{0} / 2, E_{0}\right]$

\footnotetext{
${ }^{33}$ We choose a low value of $l$ so that the curves do not cross and we get a cleaner picture. For higher values of $l$ the equityholders' and debtholders' payoffs intersect, and for even higher ones, the latter can exceed the former.

${ }^{34}$ Again, $x_{E} \in\{-1,0,1\}$, and $x_{D} \in\{0,1\}$ are the possible trading positions of the fund in equity and debt. As before for proposals $E \in\left[0, E_{0}\right]$ pure debtholders accept, while for $E \in\left(E_{0}, y\right]$ they reject. This is relevant in the
} 


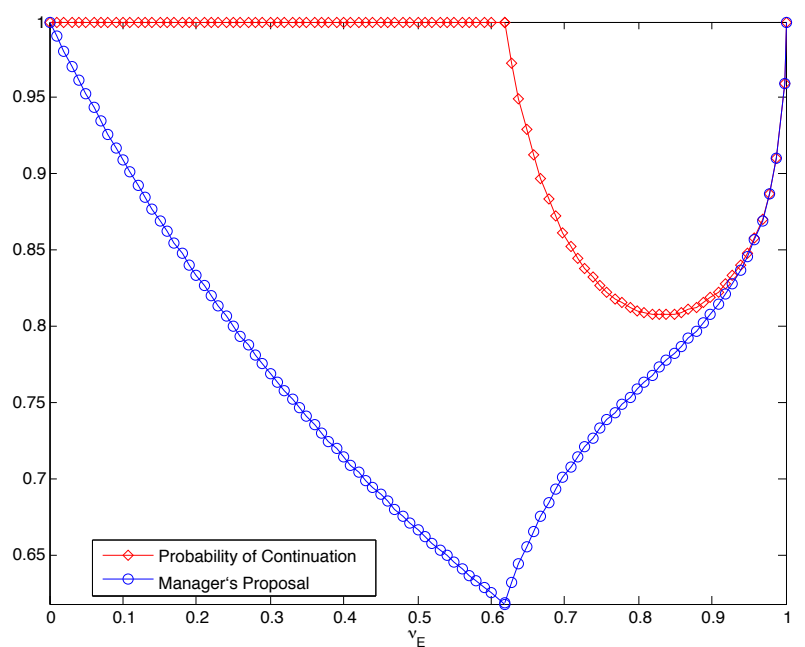

(a)

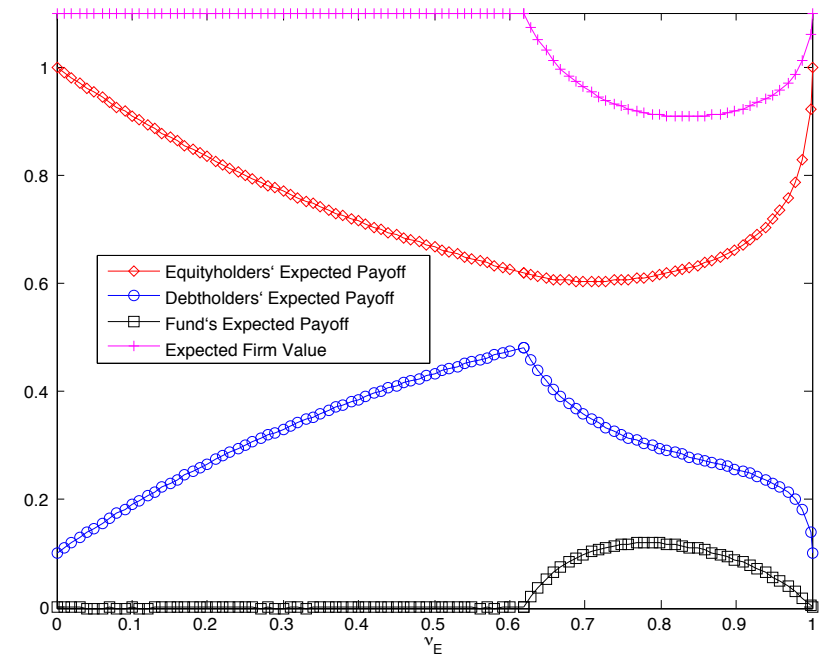

(b)

Figure 4: Numerical illustration of several equilibrium quantities vs. the probability of others going long in the equity market $\nu_{E} \in(0,1)\left(E_{0}=1\right.$ and $\left.l=0.1\right)$. In the left panel we have the manager's proposal and the probability of continuation. In the right panel we have the expected payoffs of the equityholders, the debtholders and the fund, as well as the expected firm value.

the fund's profit is equal to,

$$
\Pi_{C}^{\operatorname{Int}}\left(x_{E}, x_{D} ; E\right)=\left\{\begin{array}{cc}
y-\mathbb{E}\left[p_{E} \mid x_{E}=1, x_{D}=1\right]-\mathbb{E}\left[p_{D} \mid x_{E}=1, x_{D}=1\right], & x_{E}=1, x_{D}=1, \\
E-\mathbb{E}\left[p_{E} \mid x_{E}=1, x_{D}=0\right], & x_{E}=1, x_{D}=0, \\
y-E-\mathbb{E}\left[p_{D} \mid x_{E}=0, x_{D}=1\right], & x_{E}=0, x_{D}=1, \\
0, & x_{E}=0, x_{D}=0, \\
l+\mathbb{E}\left[p_{E} \mid x_{E}=-1, x_{D}=1\right]-\mathbb{E}\left[p_{D} \mid x_{E}=-1, x_{D}=1\right], & x_{E}=-1, x_{D}=1, \\
-E+\mathbb{E}\left[p_{E} \mid x_{E}=-1, x_{D}=0\right], & x_{E}=-1, x_{D}=0 .
\end{array}\right.
$$

Notice how each expectation over the market prices of debt $p_{D}$ and equity $p_{E}$ now depends on both trading positions, since both aggregate demands (i.e., demands of the fund together with those of other investors) are observed across the two markets. Similarly, for proposals $E \in\left(E_{0}, y\right]$, the profit of the fund in each case is

$$
\Pi_{L}^{\mathrm{Int}}\left(x_{E}, x_{D} ; E\right)=\left\{\begin{array}{cc}
y-\mathbb{E}\left[p_{E} \mid x_{E}=1, x_{D}=1\right]-\mathbb{E}\left[p_{D} \mid x_{E}=1, x_{D}=1\right], & x_{E}=1, x_{D}=1, \\
-\mathbb{E}\left[p_{E} \mid x_{E}=1, x_{D}=0\right], & x_{E}=1, x_{D}=0, \\
l-\mathbb{E}\left[p_{D} \mid x_{E}=0, x_{D}=1\right], & x_{E}=0, x_{D}=1, \\
0, & x_{E}=0, x_{D}=0, \\
l+\mathbb{E}\left[p_{E} \mid x_{E}=-1, x_{D}=1\right]-\mathbb{E}\left[p_{D} \mid x_{E}=-1, x_{D}=1\right], & x_{E}=-1, x_{D}=1, \\
\mathbb{E}\left[p_{E} \mid x_{E}=-1, x_{D}=0\right], & x_{E}=-1, x_{D}=0 .
\end{array}\right.
$$

case where the fund chooses not to trade in debt $\left\{x_{D}=0\right\}$, since then it cannot affect the outcome. Also, we have the same 'indifference' equilibrium as for segregated markets when the proposal $E \in\left[0, E_{0} / 2\right]$. 
We again use weak dominance to simplify the fund's trading choice.

Lemma 2. We have:

(i) For $E \in\left(E_{0} / 2, E_{0}\right]$

$$
\begin{aligned}
\left\{x_{E}=-1, x_{D}=0\right\} \preceq & \left\{x_{E}=0, x_{D}=0\right\} \preceq\left\{x_{E}=1, x_{D}=0\right\}, \quad \text { and } \\
& \left\{x_{E}=0, x_{D}=1\right\} \preceq\left\{x_{E}=1, x_{D}=0\right\} .
\end{aligned}
$$

(ii) For $E \in\left(E_{0}, y\right]$

$$
\begin{aligned}
&\left\{x_{E}=1, x_{D}=0\right\} \preceq\left\{x_{E}=0, x_{D}=0\right\} \preceq\left\{x_{E}=-1, x_{D}=0\right\}, \quad \text { and } \\
&\left\{x_{E}=0, x_{D}=1\right\} \preceq\left\{x_{E}=-1, x_{D}=0\right\} .
\end{aligned}
$$

Note that in Lemma 2 (in contrast to Lemma 1 ) for $E \in\left(E_{0} / 2, E_{0}\right.$ ] we cannot determine whether the fund will become pivotal or not when it is long the equity of the firm solely based on weak dominance as we did in the case of segregated markets, $\left\{x_{E}=1, x_{D}=0\right\} \npreceq\left\{x_{E}=1, x_{D}=1\right\}$. Similarly, for $E \in\left(E_{0}, y\right]$ we cannot rule out the case that the fund short-sells the equity of the firm but does not become pivotal, $\left\{x_{E}=-1, x_{D}=0\right\} \npreceq\left\{x_{E}=-1, x_{D}=1\right\}$.

By ignoring weakly dominated strategies the fund's profit for $E \in\left(E_{0} / 2, E_{0}\right]$ is

$\Pi_{C}^{\mathrm{Int}}\left(x_{E}, x_{D} ; E\right)=\left\{\begin{array}{cc}y-\mathbb{E}\left[p_{E} \mid x_{E}=1, x_{D}=1\right]-\mathbb{E}\left[p_{D} \mid x_{E}=1, x_{D}=1\right], & x_{E}=1, x_{D}=1, \\ E-\mathbb{E}\left[p_{E} \mid x_{E}=1, x_{D}=0\right], & x_{E}=1, x_{D}=0, \\ l+\mathbb{E}\left[p_{E} \mid x_{E}=-1, x_{D}=1\right]-\mathbb{E}\left[p_{D} \mid x_{E}=-1, x_{D}=1\right], & x_{E}=-1, x_{D}=1,\end{array}\right.$

while for $E \in\left(E_{0}, y\right]$ it is

$\Pi_{L}^{\mathrm{Int}}\left(x_{E}, x_{D} ; E\right)=\left\{\begin{array}{cc}y-\mathbb{E}\left[p_{E} \mid x_{E}=1, x_{D}=1\right]-\mathbb{E}\left[p_{D} \mid x_{E}=1, x_{D}=1\right], & x_{E}=1, x_{D}=1, \\ l+\mathbb{E}\left[p_{E} \mid x_{E}=-1, x_{D}=1\right]-\mathbb{E}\left[p_{D} \mid x_{E}=-1, x_{D}=1\right], & x_{E}=-1, x_{D}=1 . \\ \mathbb{E}\left[p_{E} \mid x_{E}=-1, x_{D}=0\right], & x_{E}=-1, x_{D}=0 .\end{array}\right.$

Both market-makers observe $y_{E}=x_{E}+z_{E}$ and $y_{D}=x_{D}+z_{D}$, where others' trading as summarized by $\nu_{E}, \nu_{D} \in(0,1)$ is as in the case of segregated markets. Prices for equity and debt are set according to the following equations

$$
\begin{aligned}
p_{E} & =\mathbb{E}\left[\mathbb{I}(\text { continuation }) E \mid y_{E}, y_{D}\right]=\mathbb{P}\left[\text { continuation } \mid y_{E}, y_{D}\right] E, \\
p_{D} & =\mathbb{E}\left[\mathbb{I}(\text { continuation })(y-E) \mid y_{E}, y_{D}\right]+\mathbb{E}\left[\mathbb{I}(\text { liquidation }) l \mid y_{E}, y_{D}\right] \\
& =\mathbb{P}\left[\text { continuation } \mid y_{E}, y_{D}\right](y-E)+\mathbb{P}\left[\text { liquidation } \mid y_{E}, y_{D}\right] l .
\end{aligned}
$$

Market-makers know that for $E \in\left[0, E_{0} / 2\right]$ liquidation happens only when the fund follows strategy $\left\{x_{E}=-1, x_{D}=1\right\}$ (and the other two strategies lead to continuation); similarly, for $E \in\left(E_{0} / 2, y\right]$ continuation happens only when the fund follows strategy $\left\{x_{E}=1, x_{D}=1\right\}$ (and 
the other two strategies lead to liquidation). Compared to the case of segregated markets marketmakers have now more information to assess the probabilities of these strategies and the ultimate outcome.

Define: $\alpha \equiv \mathbb{P}\left[x_{D}=1 \mid x_{E}=1\right]$, as the probability that the fund is pivotal given that it is long in equity; $\beta \equiv \mathbb{P}\left[x_{D}=1 \mid x_{E}=-1\right]$, as the probability that the fund is pivotal given that it is short in equity; and, again, $\lambda_{E}=\mathbb{P}\left[x_{E}=1\right]$, as the probability that the fund goes long equity. ${ }^{35} \mathrm{We}$ describe the equilibrium behavior of the fund as given by $\lambda_{E}, \alpha$, and $\beta$, and the resulting probability of continuation, for $E \in[0, y]$ in the following proposition.

Proposition 3. In the case of integrated markets the fund's trading behavior in the debt and equity markets varies as follows with the value of the proposal E:

(i) For $E \in\left[0, E_{0} / 2\right]$, the fund is indifferent on which side to trade in equity, $\lambda_{E} \in(0,1)$, and is also indifferent on whether to become pivotal, $\alpha \in(0,1)$, and $\beta \in(0,1)$; continuation occurs with probability one.

(ii) For $E \in\left(E_{0} / 2, y\right]$, the fund mixes its equity trading, $\lambda_{E}=E_{0} /(2 E)$, and becomes pivotal whether it is long or short equity, $\alpha=\beta=1$; continuation occurs with probability $\lambda_{E} \in(0,1)$.

Let us look at the different regions of Proposition 3 in more detail. For low proposals, case (i), the fund has exactly the same incentives as before: it is indifferent between all positions and makes zero profit for any proposal in that range. For any other proposal, case (ii), the informational integration of the two markets leads the fund to mix aggressively (i.e., for the whole range of proposals) in order to make any profit; contrast this to the region of mixing, $E \in\left(E_{0} /(1+\right.$ $\left.\nu_{E}\right), \min \left\{E_{0} / \nu_{E}, y\right\}$ ), in the case of segregated markets (Proposition 1). To gain some intuition on case (ii) of Proposition 3 assume that $E \in\left(E_{0} / 2, E_{0}\right]$ so that a pure debtholder would accept the proposal. Then if the fund buys equity for sure, $\lambda_{E}=1$, this will not only lead to a zero profit in the equity market but will also allow the debt market-maker to infer that the fund will accept the proposal if it buys debt. This will in turn increase the price of debt, $p_{D}$, and hence the cost of the overall strategy to the fund. Similarly, if $E \in\left(E_{0}, y\right]$ (so that a pure debtholder would reject the proposal) and the fund short-sells equity for sure, $\lambda_{E}=0$, then it 'signals' that it will reject the proposal if it acquires debt and so the price of debt, $p_{D}$ again increases. Hence, mixing allows the fund to maintain some positive profits while also being able to affect the outcome by buying the debt. In other words, without this mixing, buying debt would not be optimal for some proposal values, so that becoming pivotal is not a weakly dominant strategy in integrated markets.

As is clear from the expression for the mixing probability, $E_{0} /(2 E)$, for higher proposal values the fund is more enticed to short-sell. However, neither the mixing probability nor the region where the fund mixes (case (ii) of Proposition 3) depend on others' trades (although any trading profits to the fund come, again, at the expense of other traders). Thus, Proposition 3 holds for any $\nu_{E}, \nu_{D} \in(0,1)$. The reason is that for integrated markets cross-market inferences matter much

\footnotetext{
${ }^{35}$ These probabilities depend on the region in which the possible values of the proposal lie but for notational brevity we omit this dependence.
} 
more than inferences based on knowledge of others' trading. This makes the fund very aggressive in its mixing, which translates to mixing even for very small proposal values (i.e., for proposals up to $\left.E_{0} / 2\right)$. Of course, the fund's actual profit when it plays the strategy prescribed in case (ii) of Proposition 3, depends on both the proposal $E$ and others' equity trading $\nu_{E}$ (see proof of Proposition 3 in Appendix A):

$$
\frac{\left(1-\nu_{E}\right) \nu_{E}\left(2 E-E_{0}\right) E_{0}}{2 \nu_{E} E+\left(1-2 \nu_{E}\right) E_{0}}
$$

Expression (9) is positive for all $E \in\left(E_{0} / 2, y\right], \nu_{E} \in(0,1)$ and strictly increasing in $E$ for any $\nu_{E} \cdot{ }^{36}$ In Figure 5 we plot the fund's profit as given by (9) versus the proposal $E \in\left[E_{0} / 2, y\right]$ for two different values of $\nu_{E}$ (for $E_{0}=1$ and $l=0.1$; the dotted vertical line signifies $E_{0}=1$ ). Contrast this with the corresponding figure for segregated markets, Figure 3. We see that for integrated markets the fund mixes for the whole range of proposals, and the profits are not as dissimilar between the two values of $\nu_{E}$ as they were for segregated markets.

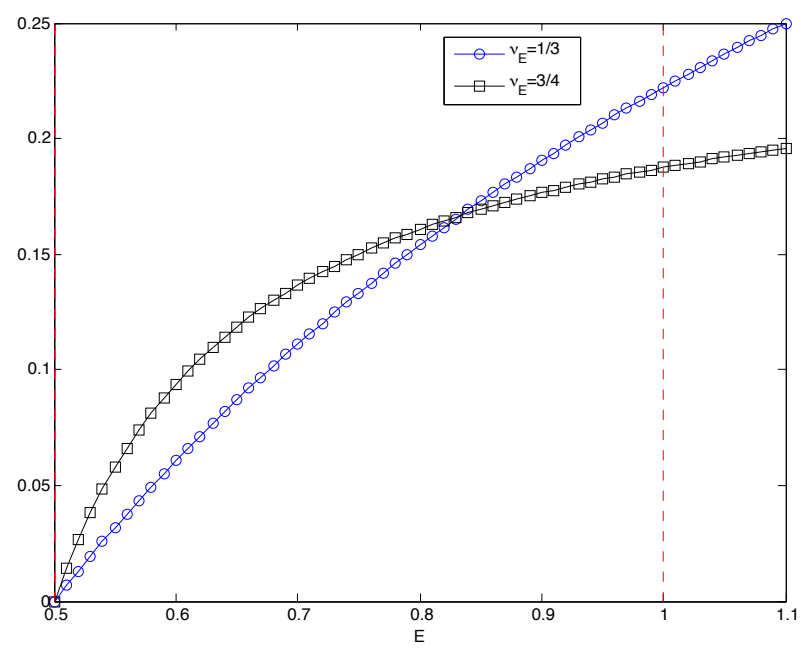

Figure 5: Numerical illustration of the fund's expected profit vs. the manager's proposal $E \in$ $\left[E_{0} / 2, y\right]$ for two different values of $\nu_{E}\left(E_{0}=1\right.$ and $\left.l=0.1\right)$.

Since for all proposals $E>E_{0} / 2$ the fund will reject with positive probability, the issue is now whether the manager will pick one of these proposals and sacrifice firm value to satisfy equityholders as she did in the case of segregated markets. Given the fund's behavior in Proposition 3 the manager has to solve the following problem,

$$
\max _{E \in[0, y]} \quad E \mathbb{I}\left(E \leq E_{0} / 2\right)+\left(E_{0} / 2\right) \mathbb{I}\left(E>E_{0} / 2\right)
$$

\footnotetext{
36

That is, $\frac{\partial}{\partial E}\left(\frac{\left(1-\nu_{E}\right) \nu_{E}\left(2 E-E_{0}\right) E_{0}}{2 \nu_{E} E+\left(1-2 \nu_{E}\right) E_{0}}\right)=\frac{\left(1-\nu_{E}\right)^{2} E_{0}^{2}}{\left(2 \nu_{E} E+\left(1-2 \nu_{E}\right) E_{0}\right)^{2}}>0$.
} 
from which it is easy to see that she is indifferent to any point $E$ between $E_{0} / 2$ and $y$. If maximizing the probability of continuation is her secondary objective then she picks $E=E_{0} / 2,{ }^{37}$ which guarantees continuation, essentially by making the fund indifferent between trading or not. So we state the following without proof.

Proposition 4. In the case of integrated markets the equilibrium strategy of the manager is to propose $E=E_{0} / 2$ that leads to continuation with probability one. The fund makes zero profit in equilibrium, while debtholders' payoff is $y-E_{0} / 2$, equityholders' is $E_{0} / 2$, and firm value is $y$.

Hence, in this case, the presence of the fund inflicts the maximum damage on equityholders since it reduces their share of the surplus to $E_{0} / 2$, which is the minimum they can get in any circumstances given our assumptions. In particular, contrasting the equityholders' payoff here with Proposition 2, we conclude that in the presence of the fund, equityholders prefer segregated markets to integrated markets, as the former lead to a higher expected payoff for equityholders (for any $\left.\nu_{E} \in(0,1)\right)$. The reverse is true for debtholders who are maximally benefited with integrated markets (since they receive $y-E_{0} / 2$ ) and hence strictly prefer them to segregated markets. In addition, these effects in integrated markets come at no forfeiture of firm value, which is $y$ since the probability of continuation is one, and so there is no deadweight loss in this case.

Let us discern the intuition for the features of the equilibrium. As before, the manager knowing the fund's strategy would make a higher proposal and risk liquidation only when some of the deadweight loss of doing so can be born by other traders - who provide an exogenous source of profit to the fund - and not by the long-term equityholders in the firm. As we saw, for the fund to make any profit in this case, it has to mix more aggressively, and as a consequence reject the proposal, and lead the firm to liquidation with positive probability for a wider range of proposals. However, the fund's ultimate decision to accept or reject the proposal, does not depend on its potential profits during the trading round. These profits are affected by the market-maker's ability to detect the fund's actions. Since the likelihood of detection is high for segregated markets, the end result is that any trading profits for the fund come at a greater loss to expected firm value. In turn the manager (i.e., the equityholders) are not willing to bear the significant deadweight loss and so the manager has no other option but to make a low proposal that guarantees continuation. The outcome (no inefficient liquidation) is the same as for segregated markets when $\nu_{E}<\underline{\nu_{E}}$, see case (i) of Proposition 2. The essential difference being that here the result holds for any $\nu_{E} \in(0,1)$ due to the integrated nature of markets.

It is the fund's mere presence that changes the incentives of the manager in making the proposal. The fund here is the equivalent of a 'credible threat' by the debtholders to the manager that if she does not give them the maximum allowed payoff then the fund will destroy some of the firm value. The threat is credible because the fund still has incentives to short-sell and make profits off other traders if the manager makes a proposal $E>E_{0} / 2$. However, other traders are not sufficient to offer the same external source of profit as before that would allow the long-term equityholders to

\footnotetext{
${ }^{37}$ This is a reasonable assumption to make since, although the manager is indifferent, she would otherwise be deliberately hurting firm value by proposing $E>E_{0} / 2$ without increasing the equityholders' expected payoff.
} 
also benefit from their existence, as in segregated markets.

\section{Implications and Further Issues}

In this section we indicate how our framework can be modified to address closely related issues, present an extension where we endogenize others' trades, and discuss the implications of our results.

\subsection{Ex-ante Trade}

In Sections 4-5 we considered the case where there is trade only following the manager's proposal. An alternative would be to have trade before but not after the proposal. If there is trade before the proposal and the manager observes the fund's resulting positions then we are in the benchmark case we analyzed in Section 3, where we showed that the manager can always find a proposal to guarantee continuation. On the other hand, if the manager just observes aggregate order flows (or equivalently prices) then she can only imperfectly infer the fund's positions. She then uses this information to decide on the proposal. By having trade, as in Sections $4-5$, only following the proposal we do not give the manager such informational advantage. Moreover, even though the manager makes her choice first and so commits to a particular proposal this does not give any extra information to the fund. So, the subgame perfect equilibria we calculate by backward induction in Sections 4-5 are (some of the) equilibria of a (hypothetical) simultaneous move game between the manager and the fund. Therefore, we expect the outcome, when there is only trade before the proposal, to be a 'convex combination' of the outcome in the complete information case (Section 3) and of the equilibria we describe in Sections 4-5. In particular, we still expect liquidation to occur with positive probability under similar market conditions.

\subsection{Credit Default Swaps}

A CDS (or similarly a recovery swap) that is triggered by liquidation is an asset that pays zero if there is continuation and pays a positive nominal amount otherwise. So in the context of our model, a CDS claim with nominal $E$ (the proposed payment to equityholders) is equivalent to a short equity claim plus a certain amount $E$ paid regardless of the outcome. This equivalence holds only if the CDS and the equity markets have equal probability (of continuation) assessments. So our model also encompasses the case in which there is no trade in equity but there is trade in CDS, even of this restrictive type. Hence our argument in favor of integration also applies between the debt and CDS markets. ${ }^{38}$

An important difference between the equity and CDS markets is that CDS contracts are in zero net-supply, essentially allowing a buyer of a CDS to overinsure by acquiring CDS that have a nominal value which is a multiple of the buyer's underlying debt positions (if any). In the context

\footnotetext{
${ }^{38}$ The equivalence of short equity claims and CDS in our framework also relies on the assumption that the proposed payoff is credible, and the continuation/liquidation values are known. Lack of credibility of the manager's proposal (e.g., due to agency problems) would not allow investors to infer the probability of continuation just by observing the price of equity or the price of debt.
} 
of our model - simplifying somewhat - this would correspond to a short position of more than one unit. As an example, consider a fund that has a 'short equity' position of two units and is also a pivotal debtholder. Then the proposal $E$ that would make the fund indifferent between liquidation and continuation is

$$
-2 E+y-E=0+l \Longleftrightarrow E=E_{0} / 3
$$

clearly less than $E_{0} / 2$, which was the case before (Section 3.2 ). Then this $E_{0} / 3$ would play exactly the same role as $E_{0} / 2$ played in our analysis. Hence, the zero net-supply nature of derivatives' markets would lead to an even bigger 'squeeze' of value from equityholders in the restructuring procedure, but as long as the conditions we prescribed are met, firm value would not be affected even in this (modest) overinsurance case. ${ }^{39}$

\subsection{Symmetric Trading}

For others' trades in the equity market we considered the simple distribution, $z_{E} \in\{-1,+1\}$ with $\mathbb{P}\left[z_{E}=1\right]=\nu_{E}$. The single parameter $\nu_{E}$ determines both the expectation $2 \nu_{E}-1$, and the variance $4 \nu_{E}\left(1-\nu_{E}\right)$, of others' trading. Hence, a concern may be that our result about no liquidation when others' trading is symmetric - in the case where the fund trades in both debt and equity but markets are segregated (Remark 3 in Section 4 ) - is not driven by the zero expectation but by the maximum variance, which we have when $\nu_{E}=1 / 2$.

To tackle this issue we study the case where $z_{E} \in\{-1,0,1\}$ with $\mathbb{P}\left[z_{E}=1\right]=\mathbb{P}\left[z_{E}=0\right]=$ $\mathbb{P}\left[z_{E}=-1\right]=1 / 3$, so that the expectation is still zero, but the variance is lower $(2 / 3<1)$ than in the case we studied in the main text. So keeping the timing and structure of the model as in Section 4 and just changing the distribution of others' trades in the equity market we obtain the following. ${ }^{40}$

Proposition 5. In equilibrium the manager makes proposal $3 E_{0} / 4$, the fund buys debt and equity with probability one and accepts the proposal. Equityholders make $3 E_{0} / 4$; the fund makes zero and pure debtholders make $y-3 E_{0} / 4$.

Hence, also for this different distribution, but where the trades of others are again zero in expectation we still get continuation for sure in the case where the fund can trade in both debt and equity and markets are segregated. This indicates that it is the expectation of others' trades that matters on whether we get liquidation or continuation in equilibrium and not the variance. Naturally, the variance of others' trades affects the fund's trading profits in the equity market. Since the fund uses others' trades to camouflage, the more uncertain these are (as measured by their variance) the more trading profits for the fund. ${ }^{41}$ As we saw, even in the cases where the fund's trade is a 'wash', the fund's potential trading profits serve as a threat to squeeze out more value

\footnotetext{
${ }^{39}$ If the swap nominal exceeds the surplus $E_{0}=y-l$ then the manager will not be able to find a proposal to guarantee continuation (even in the complete information case) and so liquidation is imminent. It is as if one of the two bargaining parties can guarantee itself all of the available surplus if negotiations fail.

${ }^{40}$ Details of the derivation are available upon request.

${ }^{41}$ This follows directly from Kyle (1985) where the insider's trading profits increase with the variance of noise trade, which is distributed normal in that case.
} 
for debtholders in equilibrium. Hence, even in the cases with no liquidation where the fund makes zero trading profits, we expect for higher variance to have a higher payoff for pure debtholders. To see this in the context of our model note that in the segregated markets equilibrium (Proposition 2 and Corollary 1) for $\nu_{E}=1 / 2$ the proposal is $2 E_{0} / 3$ and so pure debtholders make $y-2 E_{0} / 3$, which is less than what they make under Proposition 5 above.

\subsection{Liquidation vs. Continuation}

'Liquidation' and 'continuation' are simply labels in our model, there is nothing special about them. In particular, we could instead have assumed that the liquidation value is higher than the continuation value. In that case equityholders would receive nothing under continuation and the manager's proposal would be over the split of the liquidation value; liquidation would be the efficient outcome and all our results would identically go through, with the labels 'continuation' and 'liquidation' reversed. ${ }^{42}$ Re-phrasing our results, a fund's involvement in this case may lead to inefficient continuations in exactly the same circumstances as before, i.e., segregated markets and positive expected trades by others. The fund in an inefficient continuation equilibrium buys debt and short-sells equity. Then, it rejects the proposal and forces the firm to continue its operations, with the fund and other debtholders, as the new owners of the business, and with the old equityholders completely 'squeezed out'. ${ }^{43}$ Hence, in general, the fund's presence may lead to the inefficient outcome, whichever that one may be.

\subsection{Bonds vs. Bank Debt}

Our concept of debt in the paper applies equally well to corporate bonds, either publicly traded or privately placed, and bank debt (loans), to the extent that these are traded in the secondary market. According to Howard and Hedger (2008, sec. 6.3) "commercial banks are offloading [distressed] loans because regulators under the capital and equity framework imposed by Basel II are effectively forcing them to clear their portfolios". Moreover, sale of the loans of one bank leads others to follow suit, fostering trading activity. This is also echoed in Massoud, Nandy, Saunders, and Song (2011) who document how hedge funds, during the last decade, have been heavily involved in the syndicated loans market and have stepped in to fulfill the role traditionally kept for commercial banks. Hence, our analysis and results hold also for firms with only bank debt and is applicable to loan amendments as well as debt restructurings. Naturally, if all debt is held by commercial banks and is not traded then we are in the 'pure debtholders' case (Section 3.1). On the other hand, if there is trade (and the aforementioned evidence suggests there is) then we saw that no matter whether markets are integrated or segregated (and whatever others' trades are) debtholders benefit in expectation, relative to the pure debtholders case, from a fund's presence. This is relevant

\footnotetext{
${ }^{42}$ In practice decisions over liquidation rather than continuation might be governed by other voting rules, but in our model we abstract from those, and feel that the particularities of voting rules will not affect our qualitative results.

${ }^{43}$ The outcome in this case is observationally equivalent to a loan-to-own strategy, though typically loan-to-own funds do not trade in multiple securities of a firm.
} 
when other debt investors decide on whether or not to lend to a particular firm (see also empirical prediction P2 and the ensuing discussion in Section 6.8).

\subsection{Merger Proposals}

Our model about how trading and, in particular, short-selling can affect real outcomes, and how the informational structure of markets is related to these real outcomes can be applied equally well to the study of merger proposals. ${ }^{44}$ In both debt restructurings and merger proposals there are two parties which hold tradable securities and bargain over the split of a surplus which comes from combining the underlying assets corresponding to these securities.

To adapt our analysis for merger proposals requires a simple relabelling of the main actors in the model. The 'manager/equityholders' and the 'debtholders' in our model are the equityholders of the acquirer firm (simply acquirer) and the equityholders of the target firm (simply target), respectively. The acquirer makes a take-it-or-leave-it offer on how to split the value of the combined firm to the target. As mentioned in Section 2, in merger proposals (in contrast to outside bankruptcy debt restructurings) there is a formal vote by the target. Let $V_{C}$ be the valuation of the combined firm if the offer is accepted, and let $V_{A}$ and $V_{T}$ be the standalone valuations of the acquirer and target if the offer is rejected. The merger is deemed efficient (value improving) if $V_{C}>V_{A}+V_{T}$, which captures the potential value of synergies between the two firms. Then, the fund is either an existing or a potential equityholder (or a group of equityholders) of the target who can short-sell the equity of the acquirer. ${ }^{45}$ In the cases where the shares that the fund procures in the target bear no votes then there is an inherent event risk. However, this risk is eliminated (or significantly mitigated) if the shares allow the fund to be a pivotal (or near pivotal) equityholder. For example, in the case of Henderson Investment reported in $\mathrm{Hu}$ and Black (2006, pp. 834-835) a proposal was rejected by a negative vote of just $2.7 \%$ of the outstanding shares.

Reinterpreting the main results of Sections $4-5$, the existence of the fund in this scenario has two effects: the first is that it increases the bargaining power of the target and hence it increases the share of the merger surplus the target receives; the other is that under certain circumstances the fund's presence leads to the rejection of the merger proposal with positive probability. The circumstances that lead to the inefficient outcome are: (i) when the fund is an existing equityholder of the target at the time the proposal is made; (ii) even when the fund is not an existing equityholder, if the equity markets for the shares of the target and the acquirer are segregated. In both cases, (i) and (ii) above, we also need the rest of the market to be in expectation long the equity of the acquirer. Segregation can occur if the two firms are listed in different exchanges with different liquidity characteristics, or if the 'short-sale' actually happens through an opaque derivatives market. ${ }^{46}$ Since the strategy we describe shifts value from the equityholders of the acquirer to the ones

\footnotetext{
${ }^{44}$ Several examples of hedge funds' involvement in mergers can be found in Hu and Black (2006), Hu and Black (2007), and Kahan and Rock (2007).

${ }^{45}$ This is not the typical long-the-target, short-the-acquirer merger arbitrage strategy. There the arbitrageur is speculating that the merger will happen, but there is some inefficiency so that the target's stock price is undervalued relative to the share of the consolidated profits that the equityholders of the target will receive.

${ }^{46}$ Note that this is different from the effects exhibited in Burkart and Lee (2010) where strategies rely on asymmetric
} 
of the target this may lead, in general, to a potential acquirer being less willing to make a merger proposal if it foresees the equityholders of the target short-selling its equity.

\subsection{Opportunistic Fund}

The equilibrium with liquidation in the case of segregated markets (case (ii) of Proposition 2 in Section 4) relied on the existence of other traders with positive expected trades, exogenously determined. In this subsection we show the robustness of this result by endogenizing the behavior of other traders. Assume that other traders are represented by an opportunistic fund; opportunistic in the sense that it seeks to exploit trading opportunities in the distressed equity of the firm undergoing restructuring. Since in this subsection we consider two funds, we will abbreviate the original fund as $H F$ and the opportunistic fund as $O F$ to avoid confusion.

We make a few key assumptions about the OF: (i) it starts with no positions on the securities of the firm and faces no short-selling costs/constraints; (ii) it does not trade in the firm's debt; (iii) it has a discount factor $\rho \in(1 / 2,1)$; (iv) it never chooses not to trade. Assumption (i) is the same that we made for the HF; assumption (ii) is a characteristic of many funds that are only equity focused. They are both made for simplicity. ${ }^{47}$ Assumption (iii) says that the fund wishes to make a quick turnaround as it values more the present than the future; similarly, it can be thought of as a "liquidity parameter capturing imperfect access to the capital markets" as in Glosten and Milgrom (1985, p. 77).

Assumption (iv) says that the OF will trade even when that gives it a lower payoff than not trading. To be clear, the OF can go long/short equity, understands its price impact, and will choose its action in an optimal way; we just assume that no-trading is not part of the OF's choice set. This can be justified on the grounds of churning (Trueman (1988), Allen and Gorton (1993), Dow and Gorton (1997)): the OF is willing to make even negative present value trades if it believes that this will attract more investment flows (i.e., new money to invest) in the future. ${ }^{48}$ The flow motive (Chevalier and Ellison (1997)) is typical of mutual funds, but nowadays also for hedge funds that seem to make more of their compensation from management rather than incentive fees. For a micro-foundation of how the flow motive can lead to churning see Dasgupta and Prat (2006). ${ }^{49}$

From a modelling perspective, our finding in Section 4 on the occurrence of the inefficient outcome requires the existence of other traders who create profitable opportunities for the fund. Since the market-maker makes zero in expectation, the fund's profit must come at the expense of other traders. In this extension there are no 'pure noise traders' and hence, without assumption (iv) we cannot even start thinking whether an inefficient equilibrium will arise.

information between other investors and the fund.

${ }^{47}$ It is an interesting topic for future research to consider the case of another fund that can also affect the outcome by purchasing debt as the HF in our model.

${ }^{48}$ Typically, churning is associated with lack of information and a desire to pretend to be informed by trading. Here, churning is optimal if more investment flows are attracted when the OF is seen to be taking the correct 'bet' in the liquidation/continuation of the firm, even if it loses to the HF in the actual equity trade.

${ }^{49} \mathrm{~A}$ different approach to motivate trading in this context would be to make the discount factor $\rho$ random, as in Diamond and Verrecchia (1987), so that the OF would face random 'time-preference' shocks, which would lead it to trade due to liquidity reasons. 
We are now ready to inquire as to whether in this rational model with the OF and the HF inefficiencies will occur with positive probability as they did in the presence of other traders with exogenously determined trades. The main result is summarized as follows:

With an opportunistic fund (OF) there exists an equilibrium in segregated markets such that:

(i) For $\rho \in(1 / 2,1)$ the manager's proposal is less than $E_{0}$, and so equityholders always get less than in the pure debtholders case.

(ii) For $\rho \in(3 / 4,1)$ the manager's proposal leads to liquidation with positive probability.

Hence, qualitatively, the result with the OF is identical to the one in Proposition 2 of Section 4. In particular (i) says that equityholders (debtholders) are worse (better) off in the presence of the $\mathrm{HF}$, regardless of whether an inefficiency occurs in equilibrium. More importantly, (ii) says that inefficiencies do occur for a range of values of the discount factor $\rho .^{50}$

The analysis, which appears in Appendix B, is more involved than the corresponding one in Section 4 due to the presence of another strategic player, the OF. In Appendix B we first derive, in Lemma 3, the optimal trading strategy of the OF for any strategy of the HF. Then, in Proposition 6 , we use the dependence of the OF's strategy on the HF's strategy to derive the HF's optimal strategy. Given the OF's and the HF's optimal trading strategies we solve the manager's problem for the equilibrium proposal in Proposition 7. Then, in Corollary 2, we present the expected payoff of the equityholders, the debtholders, the HF and the OF, as well as the expected firm value all in equilibrium. Finally, we present a numerical example and produce Figures 6-8, which parallel Figures 2-4 of Section 4.

From (26)-(27) and Figure 4 in Appendix B we see that, in equilibrium, both the OF and the HF buy equity for $\rho \in(1 / 2,3 / 4)$ and there is no liquidation, while they both mix between buying and short-selling for $\rho \in(3 / 4,1)$ and so there is a possibility of inefficient liquidation (of course the actual mixing probabilities of the HF and the OF are different). In this sense the OF is (probabilistically) following the HF and even though it loses on the actual trade between them, it can potentially attract flows by appearing to be on the 'correct' side of the market. Interestingly, although the $\mathrm{OF}$ is short-selling with positive probability for $\rho \in(3 / 4,1)$, its equity trades are in expectation long as was also the case with our other traders, with exogenously given trades, in the equilibrium with liquidation (case (ii) of Proposition 2 in Section 4). ${ }^{51}$

For Section 4 we stick to the analysis with other traders with exogenously specified trades, as the algebra is less involved, the intuition is more discernible and, as we saw from the discussion above, the qualitative result is the same.

\subsection{Empirical and Policy Implications}

The results we presented speak about the outcome of restructurings in the presence of funds that can trade in multiple securities of a firm. Our predictions are in terms of the probability of success

\footnotetext{
${ }^{50}$ See also discussion in Appendix B.

${ }^{51}$ Note that this is true without any restriction in the OF's capacity to go short in the equity market.
} 
of a restructuring proposal and the resulting split of the surplus between claimholders. These rely on measuring: (i) the integration/segregation between markets; and (ii) the (average) direction of other investors' trades in the equity of a firm.

As we mentioned in the Introduction the debt and equity markets differ significantly, primarily because equity is traded in centralized exchanges, while debt is traded in over-the-counter markets. This results in the debt market lagging behind the equity market in how fast public information is incorporated into the corresponding prices (Hotchkiss and Ronen (2002) and Downing, Underwood, and Xing (2009)). This lag, which varies in the cross-section of firms and countries, can be used as a measure of integration between the equity and debt markets.

Securities in a distressed firm going through a restructuring procedure attract a lot of investor attention, see Howard and Hedger (2008, sec. 6.1). ${ }^{52}$ Delisting or suspension of trading in a firm's shares is not very common and if it happens it may just result in trading to consummate in another exchange. For example, the stock of a distressed firm in the UK can be delisted from the primary London Stock Exchange - at the discretion of the firm or the Financial Services Authority - but can still be traded at the Alternative Investment Market, which has less stringent disclosure rules (Howard and Hedger (2008, pp. 87-92)).

According to Howard and Hedger (2008, sections 6.1-6.3), the main participants in the market for distressed securities are the following: (i) private equity funds, who primarily invest only in the firm's debt in order to gain control in the case of a restructuring, in a loan-to-own strategy; (ii) long-term, buy and hold investors, like debt-focused mutual/pension funds, who trade on the senior tranches of the debt; (iii) short-term, trade-motivated investors who seek to exploit trading opportunities in the securities, debt or equity, of the distressed firm. In the nomenclature of our model, (i) and (ii) are what we call pure debtholders, while (iii) is the fund of Sections 4-5, as well as the opportunistic fund of the previous subsection. So other traders in our model are equityfocused institutional investors, e.g., hedge funds specializing in distressed equity. It is those other investors' propensity to go in aggregate long or short that we need to empirically inquire into. ${ }^{53}$ As highlighted in Section 6.7, these investors might be flow motivated in their equity trades. However, they may also differ in their capacity to short-sell. In particular, mutual/pension funds face shortselling binding constraints as they have an investment mandate that prohibits them to short-sell, while hedge funds are unconstrained (see also Boehmer, Jones, and Zhang (2008) and Engelberg, Reed, and Ringgenberg (2012) for studies on the 'identity' of short-sellers).

Having measured market segregation/integration and the direction of others' trades our predictions in terms of the probability of occurrence of the inefficient outcome are:

P1: Inefficiencies are likely to occur if markets are segregated and on aggregate others' trades are

\footnotetext{
${ }^{52}$ The referenced section in Howard and Hedger (2008) discusses debt trading, but since in practice there are many tranches of debt (e.g., $2^{\text {nd }}$ lien, mezzanine) and in our model only one, some of the discussion on 'debt' trading also relates to what we call 'equity' in the model.

${ }^{53}$ We acknowledge the difficulties in gathering some of these data since identities and positions of individuals traders are, at best, imperfectly observed ex-post. This difficulty has been recognized before by empirical papers in this area (e.g., Danis (2012)).
} 
positive in expectation (Proposition 2) $;^{54}$ if others' trading is zero in expectation (Remark 3 ) or markets are integrated (Proposition 4) there will be no inefficiency.

In terms of split of surplus comparing cases in which funds are present versus not:

P2: In restructurings where a fund is present (either before or after the proposal) debtholders receive more of the available surplus (discussions after Proposition 2 and Proposition 4).

In accordance with this Bharath, Panchapegesan, and Werner (2007) observe in the data that post '00 debtholders seem to benefit more during Chapter 11 renegotiations. ${ }^{55}$ Importantly, P2 also implies that investors will be willing to lend at least as much to a firm that has (or potentially will have) a strategic investor, like the fund in our model, as a creditor, relative to an otherwise identical firm where most debt is held by commercial banks and will not be traded.

Moreover, irrespective of the time of entry and expectation of others' trading:

P3: Debtholders receive at least as much of the available surplus when a firm's securities trade in integrated versus segregated markets (discussion after Proposition 4); conversely for equityholders. ${ }^{56}$

The above also affects the initial financing decision of the firm and in particular the extent to which it can borrow in the debt market. So, in the cross-section of firms:

P4: Firms with securities that trade in integrated markets have a higher debt capacity than those which trade in segregated markets, all else equal.

Our results point to two distinct directions for the possible resolution of inefficiencies. The first is regulatory: either there should be a ban on short-selling following the proposal, or 'hedged' debtholders should not be allowed to have a say on the proposed restructuring. Regarding the latter, the US Bankruptcy Code indeed allows a bankruptcy judge to disallow votes by creditors who may vote in 'bad faith', and the Delaware Supreme Court acknowledged recently the problem of disentangling voting power from economic exposure (for more details see Spamann (2012, Section 4.3)). These are definitely steps in the right direction, but may not apply to out-of-court restructurings that are very much unregulated. In the European Union there has been a motion towards prohibiting short-selling in 'exceptional circumstances' but member countries, primarily the UK, are not in favour. ${ }^{57}$ Even if some regulation is implemented, investors can still devise synthetic shorts (using derivatives) that are harder to monitor and regulate. Any effort to increase transparency of course in these markets is welcome.

The second is market-driven: there should be exchange of timely information across markets for different securities of the same firm and market-makers should use that information in setting the

\footnotetext{
${ }^{54}$ This is also true if the fund is an existing pivotal debtholder and only trades in the firm's equity (Remark 2).

${ }^{55}$ Arguably, there are other reasons why the presence of a pivotal fund may help debtholders in a debt renegotiation, as such resolving collective action problems between a dispersed debtholder base.

${ }^{56}$ We say 'at least as much' because if a fund is an existing pivotal debtholder, whether markets are segregated or integrated does not play a role.

${ }^{57} \mathrm{See}$ 'EU short selling rules spark confusion' (appeared online in October 31, 2012) and 'UK wins backing on clash with EU over short selling rules' (appeared online in September 12, 2013) both available at www.ft.com.
} 
price so that we are as close as possible to the case of integrated markets. Since market-makers, in practice, accrue fees from the order flow (and not from whether the firm is liquidated inefficiently or not) it is the beneficiaries of market integration, i.e., firms themselves, that should encourage market-makers to not only compete in price, but to also 'compete in information'. Nonetheless, when a hedge fund already has a 'toehold' in the company, in that it has a pre-existing debt position, then a short-selling ban following the proposal is the only optimal solution from a firm value perspective. ${ }^{58}$

\section{Conclusions}

Debt restructurings are important corporate events that attract many hedge funds. The concern arising from the funds' involvement is that they may pursue strategies that are detrimental for the firm and its claimholders. Such a strategy is the purchase of debt and the short-selling of equity (or purchase of credit derivatives) in the same firm, followed by the rejection of an efficient proposal. A crucial question then is under which market conditions a firm's manager makes a proposal so that a fund finds it profitable to execute the above strategy. To address this we presented a simple model of a firm's debt restructuring procedure in the presence of a strategic fund.

We showed that the effect on firm value depends crucially on two market characteristics: the integration/segregation between the markets for debt and equity; and the direction of other investors' trades in the equity market. In the case of segregated markets (or when the fund is an existing pivotal debtholder) the fund's existence and its ability to short-sell equity lead to inefficiencies with positive probability when others' trading is positive in expectation. In contrast, in the case of integrated markets or when others' trading is symmetric (or deterministic) there is no detrimental effect on firm value. As we would expect, regardless of the effect on firm value, it is the firm's debtholders who benefit from the fund's presence, while equityholders get a lower expected value than if there are only pure debtholders.

\section{References}

Allen, F., and G. Gorton, 1993, "Churning Bubbles," Review of Economic Studies, 60, 813-836.

Ayotte, K. M., and E. R. Morrison, 2009, "Creditor Control and Conflict in Chapter 11," Journal of Legal Studies, 1, 511-551.

Bedendo, M., L. Cathcart, and L. El-Jahel, 2010, "In- and Out-of-Court Debt Restructuring in the Presence of Credit Default Swaps," CAREFIN Research Paper No. 24/2010. Available at SSRN: http://ssrn.com/abstract=1799923.

Bharath, S. T., V. Panchapegesan, and I. Werner, 2007, "The Changing Nature of Chapter 11," Working Paper, University of Michigan.

\footnotetext{
${ }^{58}$ For merger proposals our empirical predictions $\mathrm{P} 1-\mathrm{P} 4$, as well as policy implications, hold given the same relabelling described in Section 6.6.
} 
Boehmer, E., C. M. Jones, and X. Zhang, 2008, "Which Shorts Are Informed?," Journal of Finance, $63,491-527$.

Bolton, P., and M. Oehmke, 2011, "Credit Default Swaps and the Empty Creditor Problem," Review of Financial Studies, 24, 2617-2655.

Brav, A., W. Jiang, and H. Kim, 2010, "Hedge Fund Activism: A Review," Foundations and Trends in Finance, 4, 1-66.

Brav, A., W. Jiang, and H. Kim, 2011, "The Real Effects of Hedge Fund Activism: Productivity, Risk, and Product Market Competition," Discussion paper, National Bureau of Economic Research.

Brav, A., W. Jiang, F. Partnoy, and R. Thomas, 2008, "Hedge Fund Activism, Corporate Governance, and Firm Performance," Journal of Finance, 63.

Brav, A., and R. D. Mathews, 2011, "Empty Voting and the Efficiency of Corporate Governance," Journal of Financial Economics, 99, 289-307.

Brunnermeier, M. K., and M. Oehmke, 2013, "Predatory Short Selling," Review of Finance, pp. $1-43$.

Burkart, M. C., and S. Lee, 2010, "Signaling in Tender Offer Games," Working Paper. Available at SSRN: http://ssrn.com/abstract=1342203.

Caballé, J., and M. Krishnan, 1994, "Imperfect Competition in a Multi-Security Market with Risk Neutrality," Econometrica, 62, 695-704.

Campello, M., and R. Matta, 2012, "Credit Default Swaps, Firm Financing and the Economy," Working Paper. Available at SSRN: http://ssrn.com/abstract=17r0066.

Chemla, G., and C. Hennessy, 2014, "Skin in the Game and Moral Hazard," Journal of Finance, pp. 1597-1641.

Chevalier, J., and G. Ellison, 1997, "Risk Taking by Mutual Funds as a Response to Incentives," Journal of Political Economy, 105, 1167-1200.

Danis, A., 2012, "Do Empty Creditors Matter? Evidence from Distressed Exchange Offers," Working Paper. Available at SSRN: http://ssrn.com/abstract=2001467.

Dasgupta, A., and A. Prat, 2006, "Financial Equilibrium with Career Concerns," Theoretical Economics, 1, 67-93.

Diamond, D. W., and R. E. Verrecchia, 1987, "Constraints on Short-selling and Asset Price Adjustment to Private Information," Journal of Financial Economics, 18, 277-311. 
Dow, J., and G. Gorton, 1997, "Noise Trading, Delegated Portfolio Management, and Economic Welfare," Journal of Political Economy, 105, 1024-1050.

Downing, C., S. Underwood, and Y. Xing, 2009, "The Relative Informational Efficiency of Stocks and Bonds: An Intraday Analysis," Journal of Financial and Quantitative Analysis, 44, 10811102.

Durfee, D., 2006, "Meet your New Bankers," CFO Magazine.

Eberhart, A. C., and L. A. Weiss, 1998, "The Importance of Deviations from the Absolute Priority Rule in Chapter 11 Bankruptcy Proceedings," Financial Management, 27, 106-110.

Economist Staff, 2009, "CDSs and Bankruptcy: No Empty Threat," The Economist (www.economist.com).

Engelberg, J., A. V. Reed, and M. C. Ringgenberg, 2012, "How are Shorts Informed? Short Sellers, News, and Information Processing," Journal of Financial Economics, Forthcoming. Available at SSRN: http://ssrn.com/abstract=153533\%.

Glosten, L., and P. Milgrom, 1985, "Bid, Ask and Transaction Prices in a Specialist Market with Heterogeneously Informed Traders," Journal of Financial Economics, 14, 71-100.

Goldstein, I., and A. Guembel, 2008, "Manipulation and the Allocational Role of Prices," Review of Economic Studies, 75, 133-164.

Gul, F., 2001, "Unobservable Investment and the Hold-Up Problem," Econometrica, 69, pp. 343376.

Hart, O., and J. Moore, 1998, "Default and Renegotiation: A Dynamic Model of Debt," Quarterly Journal of Economics, 113, 1-41.

Hotchkiss, E. S., and T. Ronen, 2002, "The Informational Efficiency of the Corporate Bond Market: An Intraday Analysis," Review of Financial Studies, 15, 1325-1354.

Howard, C., and B. Hedger, 2008, Restructuring Law \& Practice, LexisNexis, UK.

Hu, H. T., and B. S. Black, 2006, "The New Vote Buying: Empty Voting and Hidden (Morphable) Ownership," Southern California Law Review, 79, 811-908.

Hu, H. T., and B. S. Black, 2007, "Hedge Funds, Insiders, and the Decoupling of Economics and Voting Ownership: Emoty Voting and Hidden (Morphable) Ownership," Journal of Corporate Finance, 13, 343-367.

Hu, H. T., and B. S. Black, 2008, "Debt, Equity and Hybrid Decoupling: Governance and Systemic Risk Implications," European Financial Management, 14, 663-709. 
Jiang, W., K. Li, and P. Shao, 2010, "When Shareholders Are Creditors: Effects of the Simultaneous Holding of Equity and Debt by Non-commercial Banking Institutions," Review of Financial Studies, 23, 3595-3637.

Jiang, W., K. Li, and W. Wang, 2012, "Hedge Funds in Chapter 11," Journal of Finance, 67, $513-559$.

Kahan, M., and E. B. Rock, 2007, "Hedge Funds in Corporate Governance and Corporate Control," U of Penn, Inst for Law \& Econ Research Paper No. 06-16. Available at SSRN: http://ssrn.com/paper $=919881$.

Kahn, C., and A. Winton, 1998, "Ownership Structure, Speculation, and Shareholder Intervention," Journal of Finance, 53, 99-129.

Khanna, N., and R. D. Mathews, 2012, "Doing Battle with Short Sellers: The Conflicted Role of Blockholders in Bear Raids," Journal of Financial Economics, 106, 229-246.

Klein, A., and E. Zur, 2009, "Entrepreneurial Shareholder Activism: Hedge Funds and Other Private Investors," Journal of Finance, 64, 187-229.

Kyle, A. S., 1985, "Continuous Auctions and Insider Trading," Econometrica, 53, 1316-1336.

Kyle, A. S., and J.-L. Vila, 1991, "Noise Trading and Takeovers," RAND Journal of Economics, $22,54-71$.

Lau, S., 2008, "Information and Bargaining in the Hold-up Problem," RAND Journal of Economics, $39,266-282$.

Mas-Colell, A., M. D. Whinston, and J. R. Green, 1995, Microeconomic Theory, Oxford University Press.

Massoud, N., D. Nandy, A. Saunders, and K. Song, 2011, "Do Hedge Funds Trade on Private Information? Evidence from Syndicated Lending and Short-selling," Journal of Financial Economics, 99, 477-499.

Maug, E., 1998, "Large Shareholders as Monitors: Is There a Trade-Off between Liquidity and Control?," Journal of Finance, 53, 65-98.

Sakoui, A., 2008, "Private Equity Funds Focus on Distressed Debt," Financial Times (www.ft.com).

Skeel, D. A., and F. Partnoy, 2006, "The Promise and Perils of Credit Derivatives," U of Penn, Inst for Law 8 Econ Research Paper No. 06-22. Available at SSRN: http://ssrn.com/paper=929747.

Spamann, H., 2012, "Derivatives Trading and Negative Voting," Harvard Public Law Working Paper No. 730. Available at SSRN: http://ssrn.com/abstract=2144552.

Taub, S., 2005, "Hedge Fund Bankruptcy Role Seen Probed," CFO Magazine. 
Trueman, B., 1988, "A Theory of Noise Trading in Securities Markets," The Journal of Finance, 43, 83-95.

Yavorsky, A., G. Bauer, D. Gates, and T. Marshella, 2009, Analyzing the Potential Impact of Credit Default Swaps in Workout Situations, Moody's Investors Services, New York, NY.

\section{Appendices}

\section{A Proofs of Sections $4-5$}

Proof of Lemma 1. We consider two cases depending on whether pure debtholders decide to accept or reject the proposal.

Case 1: $E \in\left(E_{0} / 2, E_{0}\right]$. We know that $p_{E}$ is the (perceived by the market) probability of continuation times $E$, while $p_{D}$ is the probability of continuation times $y-E$ plus the probability of liquidation times $l$. In particular the expectation over $p_{E}$ can never exceed $E$. So strategy $\left\{x_{E}=-1, x_{D}=0\right\}$ is weakly dominated by $\left\{x_{E}=0, x_{D}=0\right\}$, which is, in turn, weakly dominated by strategy $\left\{x_{E}=1, x_{D}=0\right\}$. We now show that the fund always finds it optimal to be pivotal when it is long equity. It suffices to show that

$$
y-E \geq \mathbb{E}\left[p_{D} \mid x_{D}=1\right],
$$

for $E \in\left(E_{0} / 2, E_{0}\right]$. Recall that the debt market-maker observes only $y_{D}$ in this case and sets the price of debt as

$$
p_{D}=\left(1-\mathbb{P}\left[\text { liquidation } \mid y_{D}\right]\right)(y-E)+\mathbb{P}\left[\text { liquidation } \mid y_{D}\right] l \text {. }
$$

Since $E$ is common knowledge right after the proposal and before trading, when the fund calculates $\mathbb{E}\left[p_{D} \mid x_{D}=1\right]$ the expectation is over the possible values of $y_{D}$ conditional on $x_{D}=1$. Let $\mathbb{P}_{m k t}\left[\right.$ liquidation $\mid x_{D}=1$ ] be the fund's expectation over the debt market perceived probability of liquidation (i.e., $\mathbb{P}\left[\right.$ liquidation $\left.\mid y_{D}\right]$ ) conditional on the fund going long in the debt market $\left\{x_{D}=1\right\} .59$ Then,

$$
\mathbb{E}\left[p_{D} \mid x_{D}=1\right]=\left(1-\mathbb{P}_{m k t}\left[\text { liquidation } \mid x_{D}=1\right]\right)(y-E)+\mathbb{P}_{m k t}\left[\text { liquidation } \mid x_{D}=1\right] l .
$$

Since $E \leq E_{0}$ we have $y-E \geq l$, and $y-E$ is greater or equal to the convex combination of itself and something smaller. Hence, strategy $\left\{x_{E}=1, x_{D}=0\right\}$ is weakly dominated by strategy $\left\{x_{E}=1, x_{D}=1\right\}$.

Case 2: $\underline{E \in\left(E_{0}, y\right]}$. Similarly as above, strategy $\left\{x_{E}=1, x_{D}=0\right\}$ is weakly dominated by $\left\{x_{E}=\right.$ $\left.0, x_{D}=0\right\}$, which is, in turn, weakly dominated by strategy $\left\{x_{E}=-1, x_{D}=0\right\}$. We now

\footnotetext{
${ }^{59}$ Both the market perceived probability of liquidation and its expectation by the fund depend on the value of the proposal $E$ but this is suppressed for notational brevity.
} 
show that the fund always finds it optimal to be pivotal when it short-sells equity. It suffices to show that

$$
l \geq \mathbb{E}\left[p_{D} \mid x_{D}=1\right],
$$

for $E \in\left(E_{0}, y\right]$. We have,

$$
\mathbb{E}\left[p_{D} \mid x_{D}=1\right]=\left(1-\mathbb{P}_{m k t}\left[\text { liquidation } \mid x_{D}=1\right]\right)(y-E)+\mathbb{P}_{m k t}\left[\text { liquidation } \mid x_{D}=1\right] l .
$$

Since $E>E_{0}$ we have $l>y-E$, and $l$ is greater or equal to the convex combination of itself and something smaller. Hence, strategy $\left\{x_{E}=-1, x_{D}=0\right\}$ is weakly dominated by strategy $\left\{x_{E}=-1, x_{D}=1\right\}$.

Proof of Proposition 1. For the equilibrium in the case where $E \in\left[0, E_{0} / 2\right]$ see the main text. Now for $E \in\left(E_{0} / 2, y\right]$ we have

$$
\begin{aligned}
\mathbb{E}\left[p_{E} \mid x_{E}=1\right] & =\mathbb{E}\left[p_{E} \mid y_{E}=2\right] \mathbb{P}\left[z_{E}=1\right]+\mathbb{E}\left[p_{E} \mid y_{E}=0\right] \mathbb{P}\left[z_{E}=-1\right] \\
& =E \nu_{E}+\left(1-\nu_{E}\right) P_{0}, \\
\mathbb{E}\left[p_{E} \mid x_{E}=-1\right] & =\mathbb{E}\left[p_{E} \mid y_{E}=0\right] \mathbb{P}\left[z_{E}=1\right]+\mathbb{E}\left[p_{E} \mid y_{E}=-2\right] \mathbb{P}\left[z_{E}=-1\right] \\
& =\nu_{E} P_{0},
\end{aligned}
$$

where $P_{0}$ is the equity market maker's updated expectation of the probability of continuation given an observed aggregate order of zero (i.e., $\left.y_{E}=0\right)$ from (3),

$$
P_{0} \equiv \frac{\left(1-\nu_{E}\right) \lambda_{E}}{\left(1-\nu_{E}\right) \lambda_{E}+\nu_{E}\left(1-\lambda_{E}\right)} E
$$

Then the fund will choose an action according to the following relation

$$
\begin{aligned}
\Pi^{\operatorname{Seg}}(1 ; E) & \gtrless \Pi^{\operatorname{Seg}}(-1 ; E) \Longleftrightarrow y-\mathbb{E}\left[p_{E} \mid x_{E}=1\right] \gtrless l+\mathbb{E}\left[p_{E} \mid x_{E}=-1\right] \Longleftrightarrow \\
E_{0} & \gtrless P_{0}+E \nu_{E} .
\end{aligned}
$$

We first inquire for pure strategy and then mixed strategy equilibrium.

(i) Is $\lambda_{E}=0$ an equilibrium? For $\lambda_{E}=0$ from (12) $P_{0}=0$ and so from (13) we would need $E_{0}<E \nu_{E}$ or $E>E_{0} / \nu_{E} \cdot{ }^{60}$

(ii) Is $\lambda_{E}=1$ an equilibrium? For $\lambda_{E}=1$ from (12) $P_{0}=E$ and so from (13) we would need $E_{0}>E\left(1+\nu_{E}\right)$ or $E<E_{0} / 1+\nu_{E}$.

\footnotetext{
${ }^{60}$ Throughout the proof we assume that $\nu_{E} \in(0,1)$.
} 
(iii) Is $\lambda_{E} \in(0,1)$ an equilibrium? For a mixed equilibrium from (13) and (12) we need

$$
E_{0}-E \nu_{E}=\frac{\left(1-\nu_{E}\right) \lambda_{E}}{\left(1-\nu_{E}\right) \lambda_{E}+\nu_{E}\left(1-\lambda_{E}\right)} E \Longleftrightarrow \lambda_{E}=\nu_{E} \frac{E_{0} / E-\nu_{E}}{E_{0} / E\left(2 \nu_{E}-1\right)-\left(2 \nu_{E}^{2}-1\right)} .
$$

Now we show that for $E \in\left(E_{0} /\left(1+\nu_{E}\right), E_{0} / \nu_{E}\right)$ this is a well defined probability $\lambda_{E} \in(0,1)$. Note that,

$-E_{0} / E-\nu_{E}>0 \Longleftrightarrow E<E_{0} / \nu_{E}$,

- Given the above,

* For $\nu_{E}>1 / 2$

$$
E_{0} / E\left(2 \nu_{E}-1\right)-\left(2 \nu_{E}^{2}-1\right)>\nu_{E}\left(2 \nu_{E}-1\right)-\left(2 \nu_{E}^{2}-1\right)=1-\nu_{E}>0
$$

* For $\nu_{E}<1 / 2$

$$
E_{0} / E\left(2 \nu_{E}-1\right)-\left(2 \nu_{E}^{2}-1\right)>\left(1+\nu_{E}\right)\left(2 \nu_{E}-1\right)-\left(2 \nu_{E}^{2}-1\right)=\nu_{E}>0
$$

- Given these

$$
\nu_{E}\left(E_{0} / E-\nu_{E}\right)<E_{0} / E\left(2 \nu_{E}-1\right)-\left(2 \nu_{E}^{2}-1\right) \Longleftrightarrow E_{0} / E<1+\nu_{E} \Longleftrightarrow E>E_{0} /\left(1+\nu_{E}\right)
$$

Furthermore for $E \notin\left(E_{0} /\left(1+\nu_{E}\right), E_{0} / \nu_{E}\right)$ we have $\lambda_{E} \notin(0,1)$. Finally, if $y<E_{0} / \nu_{E}$ then we just restrict attention to $\left(E_{0} /\left(1+\nu_{E}\right), y\right]$. Hence for $E \in\left(E_{0} /\left(1+\nu_{E}\right), \min \left\{E_{0} / \nu_{E}, y\right\}\right)$ the fund mixes between going long and short with probability $\lambda_{E}$ given above.

Proof of Proposition 2. We are looking for the maximum of $J(E)$ given by equation (5) in the interval $E \in\left[E_{0} /\left(1+\nu_{E}\right), \min \left\{E_{0} / \nu_{E}, y\right\}\right]$. In the arguments below we will look for a maximum in $E \in\left[E_{0} /\left(1+\nu_{E}\right), E_{0} / \nu_{E}\right]$. Of course if $E_{0} / \nu_{E}<y$ this is innocuous. The concern then is if $E_{0} / \nu_{E}>y$ and the maximizer we identify is larger than $y$. We will show that this is not the case.

We have that $J\left(E_{0} / \nu_{E}\right)=0<E_{0} /\left(1+\nu_{E}\right)=J\left(E_{0} /\left(1+\nu_{E}\right)\right)$, so $E_{0} / \nu_{E}$ cannot be the solution for any $\nu_{E} \in(0,1)$. So the solution is either $E_{0} /\left(1+\nu_{E}\right)$ or an internal one.

- For $\nu_{E}=1 / \sqrt{2}$ the first order condition (FOC)

$$
\overbrace{\frac{\partial J(E)}{\partial E}}^{J^{\prime}(E) \equiv}=\nu_{E} \frac{\frac{E_{0}}{E}\left(2 \nu_{E}-1\right)\left(\frac{E_{0}}{E}-2 \nu_{E}\right)+\nu_{E}\left(2 \nu_{E}^{2}-1\right)}{\left(\frac{E_{0}}{E}\left(2 \nu_{E}-1\right)-\left(2 \nu_{E}^{2}-1\right)\right)^{2}}=0
$$

has one real solution, $E_{1}=E_{0} / \sqrt{2}$, with $J\left(E_{1}\right)=E_{0} /(4(\sqrt{2}-1))>E_{0} /(1+1 / \sqrt{2})$, and second derivative equal to $(3 \sqrt{2}-4) /(1-\sqrt{2})^{3}<0$, so it is a maximum. 
- For $\nu_{E} \in(1 / 2,1 / \sqrt{2}) \cup(1 / \sqrt{2}, 1)$ the FOC has two real solutions (and no real solutions otherwise),

$$
\begin{aligned}
& E_{1} \equiv \frac{1-2 \nu_{E}+\sqrt{3-1 / \nu_{E}-2 \nu_{E}}}{1-2 \nu_{E}^{2}} E_{0}, \\
& E_{2} \equiv \frac{1-2 \nu_{E}-\sqrt{3-1 / \nu_{E}-2 \nu_{E}}}{1-2 \nu_{E}^{2}} E_{0} .
\end{aligned}
$$

- $E_{2}>E_{0} / \nu_{E}$ for all $\nu_{E} \in(0,1)$ and hence cannot be a solution.

$-E_{1}<E_{0} /\left(1+\nu_{E}\right)$ for $\nu_{E}<\sqrt{5} / 2-1 / 2$, and $E_{1} \in\left(E_{0} /\left(1+\nu_{E}\right), E_{0} / \nu_{E}\right)$ for $\nu_{E} \geq$ $\sqrt{5} / 2-1 / 2$.

$-J^{\prime}\left(E_{0} /\left(1+\nu_{E}\right)\right)<0$ for $\nu_{E}<\sqrt{5} / 2-1 / 2$, and $J^{\prime}\left(E_{0} /\left(1+\nu_{E}\right)\right) \geq 0$ for $\nu_{E} \geq \sqrt{5} / 2-1 / 2$.

$-J^{\prime}\left(E_{0} / \nu_{E}\right)<0$ for all $\nu_{E} \in(0,1)$.

Hence the solution for $\nu_{E}<\sqrt{5} / 2-1 / 2$ is $E_{0} /\left(1+\nu_{E}\right)$ with $J\left(E_{0} /\left(1+\nu_{E}\right)\right)=E_{0} /\left(1+\nu_{E}\right)$, and probability of continuation one. While for $\nu_{E} \geq \sqrt{5} / 2-1 / 2$ the solution is $E_{1}$ given by (6) with corresponding equityholders' value $J\left(E_{1}\right)$ given by $(7)$ and probability of continuation $\lambda_{E}{ }^{*}$ in (8). It is easy to see that $E_{0} /\left(1+\nu_{E}\right) \in\left(E_{0} / 2, E_{0}\right)$, and that both $E_{1}$ and $J\left(E_{1}\right)$ are greater than $E_{0} /\left(1+\nu_{E}\right)$ and less than $E_{0}$ for $\nu_{E}>\sqrt{5} / 2-1 / 2$. Since the maximizer we identified is less than $E_{0}$ it is also strictly less than $y$ and so it is the maximizer for all $E \in\left[E_{0} /\left(1+\nu_{E}\right), \min \left\{E_{0} / \nu_{E}, y\right\}\right]$.

Proof of Lemma 2. We consider two cases depending on whether pure debtholders decide to accept or reject the proposal.

Case 1: $E \in\left(E_{0} / 2, E_{0}\right]$. It is still true that

$$
\left\{x_{E}=-1, x_{D}=0\right\} \preceq\left\{x_{E}=0, x_{D}=0\right\} \preceq\left\{x_{E}=1, x_{D}=0\right\},
$$

as in the case of segregated markets, since our arguments there did not depend on the information of the market-makers (and the resulting conditioning of the fund in its calculations of expected prices). Given this first round of elimination of weakly dominated strategies we are left with $\left\{x_{E}=1, x_{D}=1\right\},\left\{x_{E}=1, x_{D}=0\right\},\left\{x_{E}=0, x_{D}=1\right\},\left\{x_{E}=-1, x_{D}=1\right\}$. The profit by playing strategy $\left\{x_{E}=0, x_{D}=1\right\}$ is

$$
y-E-\mathbb{E}\left[p_{D} \mid x_{E}=0, x_{D}=1\right],
$$

or

$$
\mathbb{P}_{m k t}\left[\text { liquidation } \mid x_{E}=0, x_{D}=1\right]\left(E_{0}-E\right)
$$

Similarly to the notation we introduced in the proof of Lemma $1, \mathbb{P}_{m k t}$ [liquidation $\mid x_{E}=$ $0, x_{D}=1$ ] here is the fund's expectation over the market perceived probability of liquidation 
(i.e., $\mathbb{P}\left[\right.$ liquidation $\left.\left.\mid y_{E}, y_{D}\right]\right)$ conditional on the fund following strategy $\left\{x_{E}=0, x_{D}=1\right\}$. Notice that this perceived probability is now the same across both the equity and debt markets since both market-makers observe each other's order flows. Correspondingly, the fund uses both of its trades to calculate this expectation. Furthermore,

$$
\begin{array}{rc}
\mathbb{P}_{m k t}\left[\text { liquidation } \mid x_{E}=0, x_{D}=1\right] & = \\
\mathbb{P}_{m k t}\left[\text { liquidation } \mid x_{E}=0, x_{D}=1, z_{E}=1, z_{D}=1\right] \mathbb{P}\left[z_{E}=1, z_{D}=1\right] & + \\
\mathbb{P}_{m k t}\left[\text { liquidation } \mid x_{E}=0, x_{D}=1, z_{E}=1, z_{D}=0\right] \mathbb{P}\left[z_{E}=1, z_{D}=0\right] & + \\
\mathbb{P}_{m k t}\left[\text { liquidation } \mid x_{E}=0, x_{D}=1, z_{E}=-1, z_{D}=1\right] \mathbb{P}\left[z_{E}=-1, z_{D}=1\right] & + \\
\mathbb{P}_{m k t}\left[\text { liquidation } \mid x_{E}=0, x_{D}=1, z_{E}=-1, z_{D}=0\right] \mathbb{P}\left[z_{E}=-1, z_{D}=0\right] & = \\
\mathbb{P}\left[x_{E}=-1, x_{D}=1 \mid y_{E}=1, y_{D}=2\right] \nu_{E} \nu_{D} & + \\
\mathbb{P}\left[x_{E}=-1, x_{D}=1 \mid y_{E}=1, y_{D}=1\right] \nu_{E}\left(1-\nu_{D}\right) & + \\
\mathbb{P}\left[x_{E}=-1, x_{D}=1 \mid y_{E}=-1, y_{D}=2\right]\left(1-\nu_{E}\right) \nu_{D} & + \\
\mathbb{P}\left[x_{E}=-1, x_{D}=1 \mid y_{E}=-1, y_{D}=1\right]\left(1-\nu_{E}\right)\left(1-\nu_{D}\right), &
\end{array}
$$

where the second equality follows by recalling that the only time liquidation occurs is when the fund plays strategy $\left\{x_{E}=-1, x_{D}=1\right\}$ so that

$$
\mathbb{P}[\text { liquidation }]=\mathbb{P}\left[x_{E}=-1, x_{D}=1\right] .
$$

Using Bayes' rule

$$
\begin{array}{r}
\mathbb{P}\left[x_{E}=-1, x_{D}=1 \mid y_{E}=1, y_{D}=2\right]=0, \\
\mathbb{P}\left[x_{E}=-1, x_{D}=1 \mid y_{E}=1, y_{D}=1\right]=0, \\
\mathbb{P}\left[x_{E}=-1, x_{D}=1 \mid y_{E}=-1, y_{D}=2\right]=0, \\
\mathbb{P}\left[x_{E}=-1, x_{D}=1 \mid y_{E}=-1, y_{D}=1\right]=0 .
\end{array}
$$

Hence,

$$
\mathbb{P}_{m k t}\left[\text { liquidation } \mid x_{E}=0, x_{D}=1\right]=0
$$

and so the profit of strategy $\left\{x_{E}=0, x_{D}=1\right\}$ is zero which is weakly dominated by all other surviving strategies, e.g., $\left\{x_{E}=1, x_{D}=0\right\}$.

Case 2: $\underline{E \in\left(E_{0}, y\right]}$. As in the case of segregated markets we still have

$$
\left\{x_{E}=1, x_{D}=0\right\} \preceq\left\{x_{E}=0, x_{D}=0\right\} \preceq\left\{x_{E}=-1, x_{D}=0\right\} .
$$

Given this first round of elimination of weakly dominated strategies we are left with $\left\{x_{E}=\right.$ $\left.1, x_{D}=1\right\},\left\{x_{E}=0, x_{D}=1\right\},\left\{x_{E}=-1, x_{D}=0\right\},\left\{x_{E}=-1, x_{D}=1\right\}$. The profit by 
playing strategy $\left\{x_{E}=0, x_{D}=1\right\}$ is

$$
l-\mathbb{E}\left[p_{D} \mid x_{E}=0, x_{D}=1\right],
$$

or

$\left(1-\mathbb{P}_{m k t}\left[\right.\right.$ liquidation $\left.\left.\mid x_{E}=0, x_{D}=1\right]\right)\left(E-E_{0}\right)=\mathbb{P}_{m k t}\left[\right.$ continuation $\left.\mid x_{E}=0, x_{D}=1\right]\left(E-E_{0}\right)$,

We have

$$
\begin{array}{r}
\mathbb{P}_{m k t}\left[\text { continuation } \mid x_{E}=0, x_{D}=1\right]= \\
\mathbb{P}\left[x_{E}=1, x_{D}=1 \mid y_{E}=1, y_{D}=2\right] \nu_{E} \nu_{D}
\end{array}+
$$

where the equality follows by recalling that the only time continuation occurs is when the fund plays strategy $\left\{x_{E}=1, x_{D}=1\right\}$ so that

$$
\mathbb{P}[\text { continuation }]=\mathbb{P}\left[x_{E}=1, x_{D}=1\right] .
$$

Using Bayes' rule again,

$$
\begin{aligned}
\mathbb{P}\left[x_{E}=1, x_{D}=1 \mid y_{E}=1, y_{D}=2\right] & =0, \\
\mathbb{P}\left[x_{E}=1, x_{D}=1 \mid y_{E}=1, y_{D}=1\right] & =0, \\
\mathbb{P}\left[x_{E}=1, x_{D}=1 \mid y_{E}=-1, y_{D}=2\right] & =0, \\
\mathbb{P}\left[x_{E}=1, x_{D}=1 \mid y_{E}=-1, y_{D}=1\right] & =0,
\end{aligned}
$$

so that

$$
\mathbb{P}_{m k t}\left[\text { continuation } \mid x_{E}=0, x_{D}=1\right]=0,
$$

and the profit of strategy $\left\{x_{E}=0, x_{D}=1\right\}$ is zero which is weakly dominated by all other surviving strategies, e.g., $\left\{x_{E}=-1, x_{D}=0\right\}$.

Proof of Proposition 3. Since the markets in debt and equity are integrated the perceived probabilities of continuation and liquidation between the two markets are going to be the same, and the fund will use both of its trading strategies to calculate the expected market assessed probability 
of liquidation $\mathbb{P}_{m k t}$ [liquidation], as in the proof of Lemma 2. We consider two cases depending on whether pure debtholders decide to accept or reject the proposal. ${ }^{61}$

Case 1: $\underline{E \in\left(E_{0} / 2, E_{0}\right]}$. We have,

$$
\Pi_{C}^{\mathrm{Int}}\left(x_{E}, x_{D} ; E\right)=\left\{\begin{array}{cc}
\mathbb{P}_{m k t}\left[\text { liquidation } \mid x_{E}=1, x_{D}=1\right] E_{0}, & x_{E}=1, x_{D}=1, \\
\mathbb{P}_{m k t}\left[\text { liquidation } \mid x_{E}=1, x_{D}=0\right] E, & x_{E}=1, x_{D}=0, \\
\left(1-\mathbb{P}_{m k t}\left[\text { liquidation } \mid x_{E}=-1, x_{D}=1\right]\right)\left(2 E-E_{0}\right), & x_{E}=-1, x_{D}=1 .
\end{array}\right.
$$

For $e \in\{-1,1\}$, and $d \in\{0,1\}$

$$
\begin{array}{rc}
\mathbb{P}_{m k t}\left[\text { liquidation } \mid x_{E}=e, x_{D}=d\right] & = \\
\mathbb{P}_{m k t}\left[\text { liquidation } \mid x_{E}=e, x_{D}=d, z_{E}=1, z_{D}=1\right] \mathbb{P}\left[z_{E}=1, z_{D}=1\right] & + \\
\mathbb{P}_{m k t}\left[\text { liquidation } \mid x_{E}=e, x_{D}=d, z_{E}=1, z_{D}=0\right] \mathbb{P}\left[z_{E}=1, z_{D}=0\right] & + \\
\mathbb{P}_{m k t}\left[\text { liquidation } \mid x_{E}=e, x_{D}=d, z_{E}=-1, z_{D}=1\right] \mathbb{P}\left[z_{E}=-1, z_{D}=1\right] & + \\
\mathbb{P}_{m k t}\left[\text { liquidation } \mid x_{E}=e, x_{D}=d, z_{E}=-1, z_{D}=0\right] \mathbb{P}\left[z_{E}=-1, z_{D}=0\right] & = \\
\mathbb{P}\left[x_{E}=-1, x_{D}=1 \mid y_{E}=e+1, y_{D}=d+1\right] \nu_{E} \nu_{D} & + \\
\mathbb{P}\left[x_{E}=-1, x_{D}=1 \mid y_{E}=e+1, y_{D}=d\right] \nu_{E}\left(1-\nu_{D}\right) & + \\
\mathbb{P}\left[x_{E}=-1, x_{D}=1 \mid y_{E}=e-1, y_{D}=d+1\right]\left(1-\nu_{E}\right) \nu_{D} & + \\
\mathbb{P}\left[x_{E}=-1, x_{D}=1 \mid y_{E}=e-1, y_{D}=d\right]\left(1-\nu_{E}\right)\left(1-\nu_{D}\right), &
\end{array}
$$

Note that

$$
\mathbb{P}[\text { liquidation }]=1-\mathbb{P}[\text { continuation }]=\mathbb{P}\left[x_{E}=-1, x_{D}=1\right],
$$

and from Bayes' rule

$$
\begin{array}{r}
\mathbb{P}\left[x_{E}=-1, x_{D}=1 \mid y_{E}=2, y_{D}=2\right]=0, \\
\mathbb{P}\left[x_{E}=-1, x_{D}=1 \mid y_{E}=2, y_{D}=1\right]=0, \\
\mathbb{P}\left[x_{E}=-1, x_{D}=1 \mid y_{E}=0, y_{D}=2\right]=K, \\
\mathbb{P}\left[x_{E}=-1, x_{D}=1 \mid y_{E}=0, y_{D}=1\right]=\Lambda, \\
\mathbb{P}\left[x_{E}=-1, x_{D}=1 \mid y_{E}=2, y_{D}=0\right]=0, \\
\mathbb{P}\left[x_{E}=-1, x_{D}=1 \mid y_{E}=0, y_{D}=0\right]=0, \\
\mathbb{P}\left[x_{E}=-1, x_{D}=1 \mid y_{E}=-2, y_{D}=2\right]=1, \\
\mathbb{P}\left[x_{E}=-1, x_{D}=1 \mid y_{E}=-2, y_{D}=1\right]=1,
\end{array}
$$

\footnotetext{
${ }^{61}$ For $E \leq E_{0} / 2$ see discussion in the main text.
} 
where $^{62}$

$$
\begin{aligned}
K & \equiv \frac{\nu_{E}\left(1-\lambda_{E}\right)}{\nu_{E}\left(1-\lambda_{E}\right)+\left(1-\nu_{E}\right) \alpha \lambda_{E}} \\
\Lambda & \equiv \frac{\nu_{E}\left(1-\nu_{D}\right)\left(1-\lambda_{E}\right)}{\left(1-\nu_{E}\right)\left(1-\nu_{D}\right) \alpha \lambda_{E}+\nu_{E}\left(1-\nu_{D}\right)\left(1-\lambda_{E}\right)+\left(1-\nu_{E}\right) \nu_{D}(1-\alpha) \lambda_{E}}
\end{aligned}
$$

so that

$$
\begin{aligned}
& \mathbb{P}_{m k t}\left[\text { liquidation } \mid x_{E}=1, x_{D}=1\right]=K\left(1-\nu_{E}\right) \nu_{D}+\Lambda\left(1-\nu_{E}\right)\left(1-\nu_{D}\right), \\
& \mathbb{P}_{m k t}\left[\text { liquidation } \mid x_{E}=1, x_{D}=0\right]=\Lambda\left(1-\nu_{E}\right) \nu_{D} .
\end{aligned}
$$

We consider the following possibilities for an equilibrium,

- If $\alpha=1$, so that the fund prefers to become pivotal when it is long in equity, then

$$
K=\Lambda=\frac{\nu_{E}\left(1-\lambda_{E}\right)}{\nu_{E}\left(1-\lambda_{E}\right)+\left(1-\nu_{E}\right) \lambda_{E}},
$$

and

$$
\Pi_{C}^{\mathrm{Int}}(1,1 ; E)=K\left(1-\nu_{E}\right) E_{0}>K\left(1-\nu_{E}\right) \nu_{D} E=\Pi_{C}^{\mathrm{Int}}(1,0 ; E)
$$

so this is an equilibrium. ${ }^{63}$

- If $\alpha=0$, so that the fund prefers not to become pivotal when it is long in equity, then

$$
\begin{aligned}
K & =1, \\
\Lambda & =\frac{\nu_{E}\left(1-\nu_{D}\right)\left(1-\lambda_{E}\right)}{\nu_{E}\left(1-\nu_{D}\right)\left(1-\lambda_{E}\right)+\left(1-\nu_{E}\right) \nu_{D} \lambda_{E}}<1,
\end{aligned}
$$

and

$\Pi_{C}^{\operatorname{Int}}(1,1 ; E)=\left(1-\nu_{E}\right)\left[\nu_{D}+\Lambda\left(1-\nu_{D}\right)\right] E_{0}>\left(1-\nu_{E}\right) \Lambda \nu_{D} E_{0}>\left(1-\nu_{E}\right) \Lambda \nu_{D} E=\Pi_{C}^{\operatorname{Int}}(1,0 ; E)$ thus this cannot be an equilibrium.

Hence, in equilibrium the fund always becomes pivotal either it is long or short in equity (i.e., $\alpha=\beta=1$ ) and $K=\Lambda$. Given this we also have that,

$$
\begin{aligned}
\mathbb{P}_{m k t}\left[\text { liquidation } \mid x_{E}=-1, x_{D}=1\right] & =K \nu_{E} \nu_{D}+\Lambda \nu_{E}\left(1-\nu_{D}\right)+\left(1-\nu_{E}\right) \nu_{D}+\left(1-\nu_{E}\right)\left(1-\nu_{D}\right) \\
& =K \nu_{E}+\left(1-\nu_{E}\right),
\end{aligned}
$$

\footnotetext{
${ }^{62}$ The probability $\mathbb{P}\left[x_{E}=-1, x_{D}=1 \mid y_{E}=-2, y_{D}=0\right]$ is omitted because the action $\left\{x_{E}=-1, x_{D}=0\right\}$ is weakly dominated.

${ }^{63}$ Throughout the proof we assume that $\nu_{E} \in(0,1)$ and $\nu_{D} \in(0,1)$.
} 
so that,

$$
\Pi_{C}^{\operatorname{Int}}(-1,1 ; E)=(1-K) \nu_{E}\left(2 E-E_{0}\right)
$$

We consider the following possibilities for an equilibrium,

- If $\lambda_{E}=1$, so that the fund prefers to go long in equity, then $K=0$ and

$$
\Pi_{C}^{\mathrm{Int}}(1,1 ; E)=0<\nu_{E}\left(2 E-E_{0}\right)=\Pi_{C}^{\mathrm{Int}}(-1,1 ; E)
$$

and this cannot be an equilibrium.

- If $\lambda_{E}=0$, so that the fund prefers to go short in equity, then $K=1$ and

$$
\Pi_{C}^{\mathrm{Int}}(-1,1 ; E)=0<\left(1-\nu_{E}\right) E_{0}=\Pi_{C}^{\mathrm{Int}}(1,1 ; E),
$$

and this also cannot be an equilibrium.

Any mixed equilibria should be such that

$$
\begin{aligned}
\Pi_{C}^{\mathrm{Int}}(-1,1 ; E) & =\Pi_{C}^{\mathrm{Int}}(1,1 ; E) \Longleftrightarrow \\
(1-K) \nu_{E}\left(2 E-E_{0}\right) & =K\left(1-\nu_{E}\right) E_{0} \Longleftrightarrow \\
\lambda_{E} & =\frac{E_{0}}{2 E},
\end{aligned}
$$

which is a well defined probability since $E>E_{0} / 2>0$.

Case 2: $\quad E \in\left(E_{0}, y\right]$. Similarly, we have

$$
\Pi_{L}^{\mathrm{Int}}\left(x_{E}, x_{D} ; E\right)=\left\{\begin{array}{cc}
\left(1-\mathbb{P}_{m k t}\left[\text { continuation } \mid x_{E}=1, x_{D}=1\right]\right) E_{0}, & x_{E}=1, x_{D}=1, \\
\left.\mathbb{P}_{m k t}\left[\text { continuation } \mid x_{E}=-1, x_{D}=1\right]\right)\left(2 E-E_{0}\right), & x_{E}=-1, x_{D}=1, \\
\left.\mathbb{P}_{m k t}\left[\text { continuation } \mid x_{E}=-1, x_{D}=0\right]\right) E, & x_{E}=-1, x_{D}=0 .
\end{array}\right.
$$

In this regime, of course, $\alpha=1$, i.e., the fund always becomes pivotal when it is long in equity. Note that

$$
\mathbb{P}_{m k t}[\text { continuation }]=1-\mathbb{P}_{m k t}[\text { liquidation }]=\mathbb{P}\left[x_{E}=1, x_{D}=1\right]
$$


so similar calculations as before yield

$$
\begin{aligned}
\mathbb{P}\left[x_{E}=1, x_{D}=1 \mid y_{E}=2, y_{D}=2\right] & =1, \\
\mathbb{P}\left[x_{E}=1, x_{D}=1 \mid y_{E}=2, y_{D}=1\right] & =1, \\
\mathbb{P}\left[x_{E}=1, x_{D}=1 \mid y_{E}=0, y_{D}=2\right] & =K^{\prime}, \\
\mathbb{P}\left[x_{E}=1, x_{D}=1 \mid y_{E}=0, y_{D}=1\right] & =\Lambda^{\prime}, \\
\mathbb{P}\left[x_{E}=1, x_{D}=1 \mid y_{E}=-2, y_{D}=2\right] & =0, \\
\mathbb{P}\left[x_{E}=1, x_{D}=1 \mid y_{E}=-2, y_{D}=1\right] & =0, \\
\mathbb{P}\left[x_{E}=1, x_{D}=1 \mid y_{E}=0, y_{D}=0\right] & =0, \\
\mathbb{P}\left[x_{E}=1, x_{D}=1 \mid y_{E}=-2, y_{D}=0\right] & =0,
\end{aligned}
$$

where $^{64}$

$$
\begin{aligned}
K^{\prime} & \equiv \frac{\left(1-\nu_{E}\right) \lambda_{E}}{\nu_{E} \beta\left(1-\lambda_{E}\right)+\left(1-\nu_{E}\right) \lambda_{E}} \\
\Lambda^{\prime} & \equiv \frac{\left(1-\nu_{E}\right)\left(1-\nu_{D}\right) \lambda_{E}}{\left(1-\nu_{E}\right)\left(1-\nu_{D}\right) \lambda_{E}+\nu_{E}\left(1-\nu_{D}\right) \beta\left(1-\lambda_{E}\right)+\nu_{E} \nu_{D}(1-\beta)\left(1-\lambda_{E}\right)}
\end{aligned}
$$

so that

$$
\begin{aligned}
\mathbb{P}_{m k t}\left[\text { continuation } \mid x_{E}=-1, x_{D}=1\right] & =K^{\prime} \nu_{E} \nu_{D}+\Lambda^{\prime}\left(1-\nu_{D}\right) \nu_{E}, \\
\mathbb{P}_{m k t}\left[\text { liquidation } \mid x_{E}=-1, x_{D}=0\right] & =\Lambda^{\prime} \nu_{E} \nu_{D} .
\end{aligned}
$$

We consider the following possibilities for an equilibrium,

- If $\beta=1$, so that the fund prefers to become pivotal when it is short equity, then

$$
K^{\prime}=\Lambda^{\prime}=\frac{\left(1-\nu_{E}\right) \lambda_{E}}{\nu_{E} \beta\left(1-\lambda_{E}\right)+\left(1-\nu_{E}\right) \lambda_{E}},
$$

and

$$
\Pi_{L}^{\mathrm{Int}}(-1,1 ; E)=\nu_{E} K^{\prime}\left(2 E-E_{0}\right)>\nu_{E} K^{\prime} E=\nu_{E} \Lambda^{\prime} E>\nu_{E} \nu_{D} \Lambda^{\prime} E=\Pi_{L}^{\mathrm{Int}}(-1,0 ; E),
$$

so this is an equilibrium.

- If $\beta=0$, so that the fund prefers not to become pivotal when it is short equity, then

$$
\begin{aligned}
K^{\prime} & =1 \\
\Lambda^{\prime} & =\frac{\left(1-\nu_{E}\right)\left(1-\nu_{D}\right) \lambda_{E}}{\left(1-\nu_{E}\right)\left(1-\nu_{D}\right) \lambda_{E}+\nu_{E} \nu_{D}\left(1-\lambda_{E}\right)}<1,
\end{aligned}
$$

\footnotetext{
${ }^{64}$ The probability $\mathbb{P}\left[x_{E}=1, x_{D}=1 \mid y_{E}=-2, y_{D}=0\right]$ is omitted because the action $\left\{x_{E}=1, x_{D}=0\right\}$ is weakly dominated.
} 
and

$$
\Pi_{L}^{\mathrm{Int}}(-1,0 ; E)=\nu_{E} \nu_{D} \Lambda^{\prime} E<\nu_{E}\left[\nu_{D}+\left(1-\nu_{D}\right) \Lambda^{\prime}\right]\left(2 E-E_{0}\right)=\Pi_{L}^{\mathrm{Int}}(-1,1 ; E),
$$

so this cannot be an equilibrium.

Hence in equilibrium, the fund always becomes pivotal irrespective of its long or short position in equity (i.e., $\alpha=\beta=1$ ) and $K^{\prime}=\Lambda^{\prime}$. Given this we also have that,

$$
\mathbb{P}_{m k t}\left[\text { liquidation } \mid x_{E}=1, x_{D}=1\right]=\left(1-K^{\prime}\right)\left(1-\nu_{E}\right),
$$

so that,

$$
\Pi_{L}^{\mathrm{Int}}(1,1 ; E)=\left(1-K^{\prime}\right)\left(1-\nu_{E}\right) E_{0}
$$

We consider the following possibilities for an equilibrium,

- If $\lambda_{E}=1$, so that the fund prefers to go long in equity, then $K^{\prime}=1$ and

$$
\Pi_{L}^{\mathrm{Int}}(1,1 ; E)=0<\nu_{E}\left(2 E-E_{0}\right)=\Pi_{L}^{\mathrm{Int}}(-1,1 ; E)
$$

so this cannot be an equilibrium.

- If $\lambda_{E}=0$, so that the fund prefers to go short in equity, then $K^{\prime}=0$ and

$$
\Pi_{L}^{\mathrm{Int}}(-1,1 ; E)=0<\left(1-\nu_{E}\right) E_{0}=\Pi_{L}^{\mathrm{Int}}(1,1 ; E),
$$

so this cannot be an equilibrium either.

Any mixed equilibria should be such that

$$
\begin{aligned}
\Pi_{L}^{\mathrm{Int}}(-1,1 ; E) & =\Pi_{L}^{\mathrm{Int}}(1,1 ; E) \Longleftrightarrow \\
K^{\prime} \nu_{E}\left(2 E-E_{0}\right) & =\left(1-K^{\prime}\right)\left(1-\nu_{E}\right) E_{0} \Longleftrightarrow \\
\lambda_{E} & =\frac{E_{0}}{2 E},
\end{aligned}
$$

which is a well defined probability since $E>E_{0} / 2$.

Hence also in this case the unique equilibrium is $\alpha=\beta=1$ and $\lambda_{E}=E_{0} /(2 E)$.

\section{B Opportunistic Fund}

As we saw the inefficient outcome in our model occurs under special circumstances: segregated markets and positive expected trades of others (case (ii) of Proposition 2). In this section we keep the assumption of segregated markets but endogenize the trades of others by introducing the 
opportunistic fund (OF) as described in Section 6.7. Our goal is to see whether this will still lead to liquidation with positive probability.

As before, the original fund (abbreviated HF here) finds it weakly dominant to buy debt (Lemma 1 ) as this does not depend on others' trades (or the manager's proposal). Again, the manager first makes her proposal, traders observe it and submit their orders, and finally the market-makers observe only their corresponding aggregate orders and set the prices of debt and equity. To ease the analysis we assume that order submission is sequential: first the HF submits its order and then the OF submits its order. Still, none observes the order of the other, orders are aggregated before they reach the market-makers, and order fulfilment happens at the same time; it is just that the OF knows that the HF has already 'committed' in its order when it decides its own. This means that we can use backward induction to calculate the equilibrium, which will thus be subgame perfect.

Moreover, note that if the OF follows a pure strategy (i.e., it always go either long or short in the equity market), the equity market-maker will infer the HF's trades and will prevent it from making any profit. The HF is then indifferent between entering the equity market or not for any proposal. In turn, the manager proposes $E_{0}$, which is accepted, and continuation happens with certainty. Hence, in what follows we focus only on finding an optimal mixed strategy for the OF. ${ }^{65}$

Lemma 3. For any equity trading strategy $\lambda_{E}$ by the $H F$, proposal $E \in\left[E_{0} / 2, y\right]$ by the manager and for discount factor $\rho \in(1 / 2,1)$ there exists an optimal mixed strategy for the OF, in terms of its probability of going long in the equity market:

$$
\nu_{E}=\frac{1-\lambda_{E}(2 \rho-1)}{1-\left(2 \lambda_{E}-1\right)(2 \rho-1)} .
$$

Proof. The OF has, by assumption, two possible actions, to buy $z_{E}=1$ or short-sell $z_{E}=-1$ equity. The future equity value is determined by the HF's action that can be summarized by $\lambda_{E}=\mathbb{P}\left[x_{E}=1\right]$, the HF's probability of going long in the equity market. Given this, the expected equity value is $\lambda_{E} E$, where $E$ is the manager's proposal, which $\lambda_{E}$ will also depend on. For any discount factor $\rho \in(1 / 2,1)$ the OF's profit from its two actions is then:

$$
\begin{aligned}
\Pi_{\mathrm{OF}}(1 ; E) & \equiv \rho \lambda_{E} E-\mathbb{E}\left[p_{E} \mid z_{E}=1\right], \text { for } z_{E}=1, \\
\Pi_{\mathrm{OF}}(-1 ; E) & \equiv \mathbb{E}\left[p_{E} \mid z_{E}=1\right]-\rho \lambda_{E} E, \text { for } z_{E}=-1
\end{aligned}
$$

This holds for all $E \in\left[E_{0} / 2, y\right]$ since for $E<E_{0} / 2$ the fund always accepts the proposal (and leads the firm to continuation) no matter the action of other traders. The expected prices are given by

$$
\begin{gathered}
\mathbb{E}\left[p_{E} \mid z_{E}=1\right]=\mathbb{E}\left[p_{E} \mid y_{E}=2\right] \mathbb{P}\left[x_{E}=1\right]+\mathbb{E}\left[p_{E} \mid y_{E}=0\right] \mathbb{P}\left[x_{E}=-1\right]=E \lambda_{E}+P_{0}\left(1-\lambda_{E}\right), \\
\mathbb{E}\left[p_{E} \mid z_{E}=-1\right]=\mathbb{E}\left[p_{E} \mid y_{E}=0\right] \mathbb{P}\left[x_{E}=1\right]+\mathbb{E}\left[p_{E} \mid y_{E}=-2\right] \mathbb{P}\left[x_{E}=-1\right]=P_{0} \lambda_{E},
\end{gathered}
$$

\footnotetext{
${ }^{65}$ Of course, the resulting equilibrium will not be unique.
} 
where, as before, $P_{0}$ given by (12), is the market maker's updated expectation of the probability of continuation given an observed aggregate order of zero (i.e., $\left.y_{E}=0\right)$ in the equity market. Then the $\mathrm{OF}$ will choose an action according to the following relation

$$
\Pi_{\mathrm{OF}}(1 ; E) \gtrless \Pi_{\mathrm{OF}}(-1 ; E) \Longleftrightarrow(2 \rho-1) \lambda_{E} E \gtrless P_{0},
$$

where we substituted from (15)-(18) above. For a mixed strategy equilibrium we need $\Pi_{\mathrm{OF}}(1 ; E)=$ $\Pi_{\mathrm{OF}}(-1 ; E)$ or by substituting for $P_{0}$ from $(12)$

$$
(2 \rho-1) \lambda_{E}=\frac{\left(1-\nu_{E}\right) \lambda_{E}}{\left(1-\nu_{E}\right) \lambda_{E}+\nu_{E}\left(1-\lambda_{E}\right)}
$$

After some algebra this yields a unique solution for $\nu_{E}$ given by (14), which is a valid mixing probability (i.e., $\left.\nu_{E} \in(0,1)\right)$ for all $\rho \in(1 / 2,1)$ and $\lambda_{E} \in(0,1) .{ }^{66}$

The mixed strategy (14) depends on $\lambda_{E}$ and $\rho$ (and implicitly on the proposal via the dependence of the optimal $\lambda_{E}$ on $E$, given in Proposition 6). ${ }^{67}$ It is easy to show that $\partial \nu_{E} / \partial \lambda_{E}>0$ for all $\rho \in(1 / 2,1)$, and $\partial \nu_{E} / \partial \rho<0$ for all $\lambda_{E} \in(0,1)$. In words, the OF goes more long as the HF goes more long, and the OF goes more long the more 'impatient' it is, i.e., for lower $\rho$. The intuition for the, more puzzling, latter statement is as follows: for lower $\rho$ the natural inclination of the OF is to go short, but $\nu_{E}$ is its mixing probability, that is the probability for which going long and short have equal payoffs; hence, to make the payoffs equal the OF has to go more long when $\rho$ is lower.

In particular in the 'limiting' cases: when the HF goes long $\lambda_{E} \rightarrow 1$ then the OF also tends to go long $\nu_{E} \rightarrow 1$ for any $\rho \in(1 / 2,1)$, while, when the HF goes short $\lambda_{E} \rightarrow 0$ the OF tends to mix by $\nu_{E} \rightarrow 1 /(2 \rho)$. In turn, when the OF becomes more 'impatient' $\rho \rightarrow 1 / 2$ then the OF tends to mix the least $\nu_{E} \rightarrow 1$, while, when the OF becomes more 'patient' $\rho \rightarrow 1$ then the OF tends to mix the most $\nu_{E} \rightarrow 1 / 2$; both of these latter limits hold for any $\lambda_{E} \in(0,1)$. Note that when $\nu_{E} \in\{1 / 2,1\}$ (i.e., when the OF's equity trade is either symmetric or deterministic and does not depend on the HF's equity trading) we know from Remark 3 that continuation is the equilibrium outcome.

Below we present the HF's optimal strategy given that the OF follows the mixed strategy (14).

Proposition 6. In the case of segregated markets and given that the OF mixes with probability (14) the HF's equity trading behavior, in terms of its probability of going long $\lambda_{E}$, varies as follows with the value of the proposal E:

(i) For $E \in\left[0, E_{0} / 2\right]$, the fund is indifferent, $\lambda_{E} \in(0,1)$; continuation occurs with probability one.

(ii) For $E \in\left(E_{0} / 2, E_{0} /(2 \rho)\right]$, it buys, $\lambda_{E}=1$; continuation occurs with probability one.

\footnotetext{
${ }^{66}$ The condition $\rho \in(1 / 2,1)$ is, actually, also necessary for the existence of a mixed strategy for the OF.

${ }^{67}$ We can also calculate the OF's payoff by playing (14): $\lambda_{E}\left[\lambda_{E}(2 \rho-1)-\rho\right] E$.
} 
(iii) For $E \in\left(E_{0} /(2 \rho), \min \left\{2 \rho E_{0}, y\right\}\right)$, it mixes,

$$
\lambda_{E}=\frac{2 \frac{E_{0}}{E}+2 \rho-1-\sqrt{\left(2 \frac{E_{0}}{E}+2 \rho-1\right)^{2}-8\left(2 \rho \frac{E_{0}}{E}-1\right)}}{4(2 \rho-1)} ;
$$

continuation occurs with probability $\lambda_{E} \in(0,1)$.

(iv) For $E \in\left[\min \left\{2 \rho E_{0}, y\right\}, y\right]$, it short-sells, $\lambda_{E}=0$; continuation occurs with probability zero.

Proof. The proof proceeds in a similar fashion to the one of Proposition 1 with the main difference that $\nu_{E}$ is now not exogenous and independent of $\lambda_{E}$ but is given by (14). In particular this affects $P_{0}$ as given by (12) where we need to substitute for the endogenously determined $\nu_{E}$ to get

$$
P_{0}=\lambda_{E}(2 \rho-1) E .
$$

The HF's decision rule is still given by (13). Substituting for $P_{0}$ from (21) and for $\nu_{E}$ from (14) it becomes

$$
\frac{E_{0}}{E} \gtrless \lambda_{E}(2 \rho-1)+\frac{1-\lambda_{E}(2 \rho-1)}{1-\left(2 \lambda_{E}-1\right)(2 \rho-1)},
$$

where we also divided by $E$ throughout. We first inquire for pure strategy and then for mixed strategy equilibrium.

(i) Is $\lambda_{E}=0$ an equilibrium? For $\lambda_{E}=0$ from (22) we need $E_{0}<E /(2 \rho)$ or $E>2 \rho E_{0}$.

(ii) Is $\lambda_{E}=1$ an equilibrium? For $\lambda_{E}=1$ from (22) we need $E_{0}>2 \rho E$ or $E<E_{0} /(2 \rho)$.

(iii) Is $\lambda_{E} \in(0,1)$ an equilibrium? For a mixed equilibrium from $(22)$ we need

$$
E_{0} / E=\lambda_{E}(2 \rho-1)+\frac{1-\lambda_{E}(2 \rho-1)}{1-\left(2 \lambda_{E}-1\right)(2 \rho-1)}
$$

After some algebra we arrive to the following equation for the optimal $\lambda_{E}$,

$$
2(2 \rho-1)^{2} \lambda_{E}^{2}-(2 \rho-1)\left(2 \frac{E_{0}}{E}+2 \rho-1\right)+2 \rho \frac{E}{E_{0}}-1=0 .
$$

The above equation has two solutions but only one that is a valid probability (i.e., $\lambda_{E} \in(0,1)$ ) for $\rho \in(1 / 2,1)$ and $E_{0} / E \in(1 /(2 \rho), 2 \rho)$. This solution is given by (20). Furthermore for $E \notin\left(E_{0} /(2 \rho), 2 \rho E_{0}\right)$ we have $\lambda_{E} \notin(0,1)$. Finally, if $y<2 \rho E_{0}$ then we restrict attention to $\left(E_{0} /(2 \rho), y\right]$. Hence, for $E \in\left(E_{0} /(2 \rho), \min \left\{2 \rho E_{0}, y\right\}\right)$ the fund mixes between going long and short with probability $\lambda_{E}$ given by (20). 
Proposition 6 has a very similar structure to Proposition 1 in the main text. There are again four regions of proposals: low proposals for which the HF is indifferent; low intermediate proposals for which the HF always goes long; high proposals for which the HF always goes short; and, most importantly, high intermediate proposals for which the HF finds it optimal to mix and hence there is a positive probability of liquidation (when the HF happens to short-sell).

The end points of these regions as well as the mixing probability (20) depend on $\rho$ as they depended on the exogenous $\nu_{E}$ in Proposition 1. In particular, as we move from $\rho=1 / 2$ to $\rho=1$ then both the 'long-only' region, case (ii) of Proposition 6, and the 'short-only' region, case (iv), are shrinking and, correspondingly, the mixing region, case (iii) is expanding. This captures the corresponding move of the OF's strategy from a deterministic strategy $\nu_{E}=1$ (for $\rho=1 / 2$ ) to a mixed strategy $\nu_{E}=1 / 2$ (for $\rho=1$ ), which allows the HF to make trading profits by also following a mixed strategy.

Moreover, $\lambda_{E}$ as given by (20) is increasing in $\rho$, for $\rho \in(1 / 2,1)$ and for fixed $E \in\left(E_{0} /(2 \rho), 2 \rho E_{0}\right)$, and it is decreasing in $E$, for $\left.E \in\left(E_{0} /(2 \rho), 2 \rho E_{0}\right)\right)$ and fixed $\rho \in(1 / 2,1)$. In particular, note that, fixing $\rho \in(1 / 2,1)$, for $E=E_{0} /(2 \rho)$ from (20) we have $\lambda_{E}=1$ and for $E=2 \rho E_{0}$ we have $\lambda_{E}=0$. In this sense the probability of going long is continuous in the end points where it is defined. Hence, as in Section 4, we can write the manager's problem here as maximizing the product of proposal $E$ times the probability of continuation $\lambda_{E}$ as given by (20), where $E \in\left[E_{0} /(2 \rho), 2 \rho E_{0}\right] .{ }^{68}$ The following proposition describes the manager's optimal decision.

Proposition 7. Given that the OF mixes with probability given by (14) and that the HF follows the strategy profile prescribed by Proposition 6 the manager's equilibrium proposal for segregated markets is as follows, depending on the value of $\rho$ :

(i) For $1 / 2<\rho \leq 3 / 4$, the manager picks

$$
E=E_{0} /(2 \rho) \in\left(2 E_{0} / 3, E_{0}\right)
$$

with

$$
J\left(E_{0} /(2 \rho)\right)=E_{0} /(2 \rho) \in\left(2 E_{0} / 3, E_{0}\right)
$$

where $J(\cdot)$ is the expected equityholders' payoff as a function of the proposal value. In this case the equilibrium probability of continuation is equal to one, i.e., the HF goes long in equilibrium. Moreover, the OF also goes long with probability one in equilibrium.

(ii) For $3 / 4<\rho<1$, she picks

$$
E=E_{1} \equiv E_{0} \frac{2[(2 \rho+1)+(2 \rho-1) \sqrt{1-\rho}]}{8+(2 \rho-1)^{2}} \in\left(E_{0} /(2 \rho), E_{0}\right)
$$

\footnotetext{
${ }^{68}$ As in Proposition 2 we will look for an optimal proposal in $E \in\left[E_{0} /(2 \rho), 2 \rho E_{0}\right]$ and once we exhibit that the optimal is below $y$ we are then going to say that it is the optimal proposal for all $E \in\left[E_{0} /(2 \rho), \min \left\{2 \rho E_{0}, y\right\}\right]$.
} 
with corresponding equityholders' payoff

$$
J\left(E_{1}\right)=E_{0} \frac{2\left[4(1-\sqrt{1-\rho})\left(\rho^{2}+1\right)-(3-\sqrt{1-\rho}) \rho+4(1+\sqrt{1-\rho}) \rho^{3}\right]}{(2 \rho-1)[(2 \rho+1)+(2 \rho-1) \sqrt{1-\rho}]\left[8+(2 \rho-1)^{2}\right]} \in\left(E_{0} /(2 \rho), E_{0}\right),
$$

and the equilibrium probability of continuation, which is the HF's equilibrium mixing strategy,

$$
\lambda_{E}^{*} \equiv \frac{4(1-\sqrt{1-\rho})\left(\rho^{2}+1\right)-(3-\sqrt{1-\rho}) \rho+4(1+\sqrt{1-\rho}) \rho^{3}}{(2 \rho-1)[(2 \rho+1)+(2 \rho-1) \sqrt{1-\rho}]^{2}} \in(0,1) .
$$

Finally, the OF's equilibrium mixing strategy is

$$
\nu_{E}^{*} \equiv \frac{2(1-\sqrt{1-\rho})-(2-\sqrt{1-\rho}) \rho-4(2+3 \sqrt{1-\rho}) \rho^{2}+4(2+\sqrt{1-\rho}) \rho^{3}}{2\left[-4(1-\sqrt{1-\rho})+(5-3 \sqrt{1-\rho}) \rho-(5-4 \sqrt{1-\rho}) \rho^{2}+4(2+\sqrt{1-\rho}) \rho^{3}-4 \rho^{4}\right]} \in(0,1) .
$$

Proof. The manager looks for a proposal $E \in\left[E_{0} /(2 \rho), 2 \rho E_{0}\right]$ to maximize,

$$
J(E)=\frac{2 \frac{E_{0}}{E}+2 \rho-1-\sqrt{\left(2 \frac{E_{0}}{E}+2 \rho-1\right)^{2}-8\left(2 \rho \frac{E_{0}}{E}-1\right)}}{4(2 \rho-1)} E,
$$

where the fraction corresponds to $\lambda_{E}$ from (20). Differentiating with respect to $E$ yields,

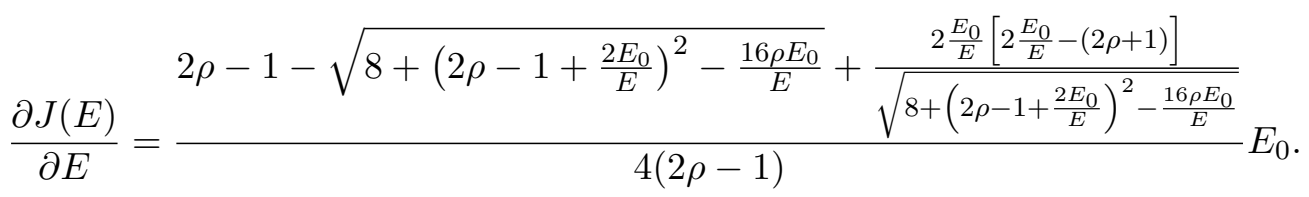

We can show after some tedious algebra that $\partial J(E) / \partial E$ is negative for all $E \in\left[E_{0} /(2 \rho), 2 \rho E_{0}\right]$ iff $\rho \in(1 / 2,3 / 4]$. Hence in this case the solution is the left corner of the domain, i.e., the maximizing proposal is $E=E_{0} /(2 \rho)$ for which from Proposition 6 the HF always goes long equity. The value for the OF's trading strategy then follows from (14) by substituting the HF's strategy.

However, for $\rho \in(3 / 4,1)$ the problem of maximizing $J(E)$ for $E \in\left[E_{0} /(2 \rho), 2 \rho E_{0}\right]$ has a unique internal solution. To find this we solve the first order condition $\partial J(E) / \partial E=0$, which yields two solutions. Only one is in $\left[E_{0} /(2 \rho), 2 \rho E_{0}\right]$ and hence this is the unique optimizer. We also check the second order condition for optimality. The formula for the solution is given by (24). The equilibrium mixing probability for the $\mathrm{HF}$ is given by (26) after we substitute the equilibrium proposal (24) in (20). The corresponding equilibrium mixing probability for the OF is given by (27) after we substitute for (26) in (14).

Finally, note that since the optimal proposal we identified is less than $E_{0}$ for all $\rho \in(1 / 2,1)$, it is also strictly less than $y$ and so it is the optimal proposal for all $E \in\left[E_{0} /(2 \rho), \min \left\{2 \rho E_{0}, y\right\}\right]$.

There are two main takeaways from Proposition 7, which are also mentioned in Section 6.7. 
First, for all $\rho \in(1 / 2,1)$ the manager makes a proposal less than $E_{0}$. This results in equityholders always receiving less than they would in the pure debtholders case. Second, for $\rho \in(3 / 4,1)$ the probability of continuation given by (26) is less than one and so in equilibrium we get liquidation with positive probability. We will discuss the features of the equilibrium in more detail in the numerical illustration below. First, we derive the debtholders', the HF's and the OF's expected payoffs, as well as the expected firm value all in the equilibrium described in Proposition 7.

Corollary 2. We have that:

(i) For $1 / 2<\rho \leq 3 / 4$ : the debtholders' payoff is $y-E_{0} /(2 \rho) \in\left(y-E_{0}, y-2 E_{0} / 3\right)$; the HF's payoff is zero; the OF's payoff is $(\rho-1) E_{0} /(2 \rho)$; firm value is $y$.

(ii) For $3 / 4<\rho<1$ : the debtholders' payoff is

$$
l+\lambda_{E}^{*}\left(E_{0}-E_{1}\right)
$$

the HF's payoff is

$$
\lambda_{E}^{*}\left[\left((2 \rho-1) \nu_{E}^{*}+1\right) E_{1}-E_{0}\right]
$$

the OF's payoff is

$$
\lambda_{E}^{*}\left[\lambda_{E}^{*}(2 \rho-1)-\rho\right] E_{1}
$$

firm value is

$$
l+\lambda_{E}^{*} E_{0}
$$

$E_{1}, \lambda_{E}^{*}$ and $\nu_{E}^{*}$ are given by (24), (26) and (27) in Proposition $\%$.

A Numerical Illustration. To illustrate the results of Lemma 3, Propositions 6 and 7, and Corollary 2 we plot several quantities of interest. The figures are going to parallel those of Section 4. In particular, Figure 6 is like Figure 2, Figure 7 is like Figure 3, and Figure 8 is like Figure 4 . The relevant comparative statics here are in terms of the proposal value $E$ and the OF's discount factor $\rho$, and not the probability of other traders going long, $\nu_{E}$ (as in Section 4), which is endogenous now. In all figures $E_{0}=1$ and $l=0.1$.

In Figure 6 we plot the expected payoff of the equityholders, the HF and the OF, as well as the firm's expected deadweight loss, all versus the manager's proposal $E \in\left[E_{0} / 2, y\right]$. In the left panel we pick $\rho=0.6$ and in the right one we pick $\rho=0.9$. As after Remark 3 in Section 4 we use this figure to illustrate three features of the equilibrium. In this context: (i) why the manager risks liquidation at all for $\rho>3 / 4$; (ii) why the manager never makes a proposal higher than $E_{0}$; (iii) why liquidation only occurs when $\rho>3 / 4$. In both panels we see that when the fund makes trading profits in the equity market this will lead to inefficient liquidations, which is related to point (i) above. More importantly, regardless of the value of $\rho$, as $E$ increases the fund's trading profits come at a much greater loss in firm value. Actually for $E \geq E_{0}=1$ (rightmost dotted vertical line in both panels) the deadweight loss becomes even more than the equityholders' expected payoff. Hence, the manager would not pick a proposal $E \geq E_{0}$, in accordance to point (ii) above. 
Now, regarding point (iii), in Figure 7 we superimpose the HF's expected payoff in the case $\rho=0.6$ from panel (a) of Figure 6 with the payoff in the case $\rho=0.9$ from panel (b) of Figure 6 . In Figure 7 the leftmost dotted vertical line corresponds to the equilibrium proposal in the case $\rho=0.9$, $E=E_{1}=0.7067$; the middle one is the equilibrium proposal for $\rho=0.6, E=E_{0} /(2 \rho)=0.8333$, and the rightmost corresponds to $E_{0}=1$. We see how for higher values of $\rho$ the fund is enticed to mix earlier and make trading profits (which cause a deadweight loss to firm value). This is why for $\rho=0.9>3 / 4$ the manager picks $E=E_{1}=0.7067$ (leftmost vertical dotted line in panel (b) of Figure 6 ) and risks liquidation, while for $\rho=0.6<3 / 4$ she picks $E=E_{0} /(2 \rho)=0.8333$ (leftmost vertical dotted line in panel (a) of Figure 6) and we get continuation for sure (Proposition 7). Observe that for the whole range of proposals in both panels of Figure 6 the OF has a negative payoff, which essentially mirrors the payoff of the HF.

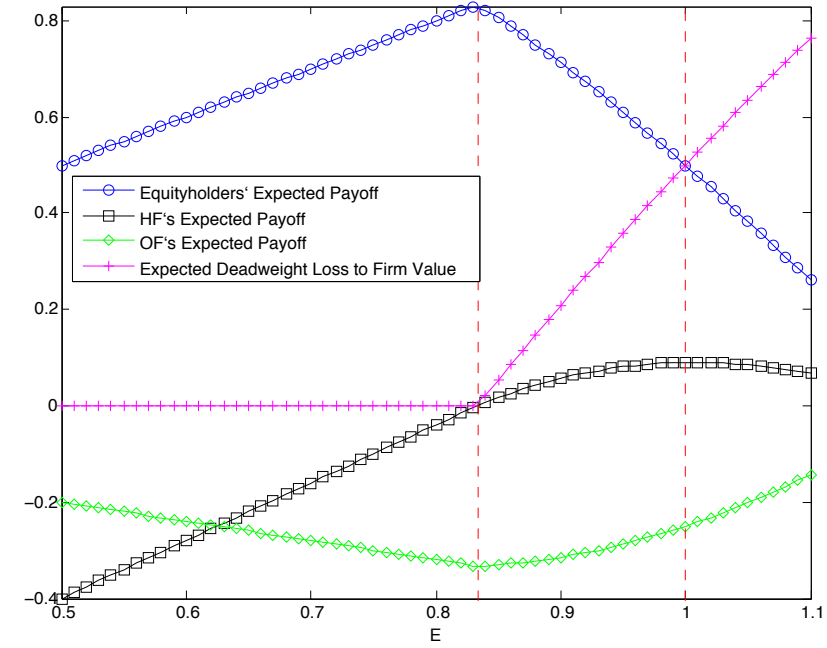

(a) $\rho=0.6$

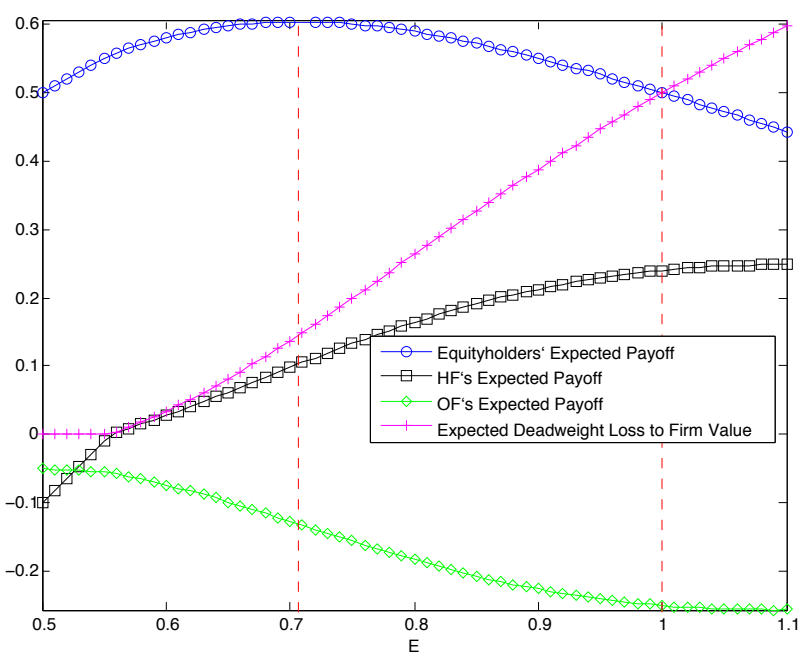

(b) $\rho=0.9$

Figure 6: Numerical illustration of the expected payoffs to the equityholders, the HF, the OF, as well as the expected deadweight loss to firm value vs. $E \in\left[E_{0} / 2, y\right]$, for $\rho=0.6$ in the left panel and $\rho=0.9$ in the right panel $\left(E_{0}=1\right.$ and $\left.l=0.1\right)$.

Finally, in Figure 8 we depict several equilibrium quantities versus $\rho \in(1 / 2,1)$. In the left panel we plot the manager's proposal, the probability of continuation, which is also the probability of the HF going long, and the probability of the OF going long, all as given by Proposition 7 . In the right panel we plot the expected payoffs of the $\mathrm{HF}$ and the $\mathrm{OF}$, together with those of the equityholders and the debtholders, as well as the expected firm value, all as given by the expressions in Corollary 2. Of course, the sum of debtholders' and equityholders' payoffs is equal to firm value. Observe that the HF in equilibrium always makes a non-negative payoff since it trades only when there is a profitable opportunity. On the other hand, the OF in equilibrium always makes a negative payoff, which maintains the trading motive for the HF. 


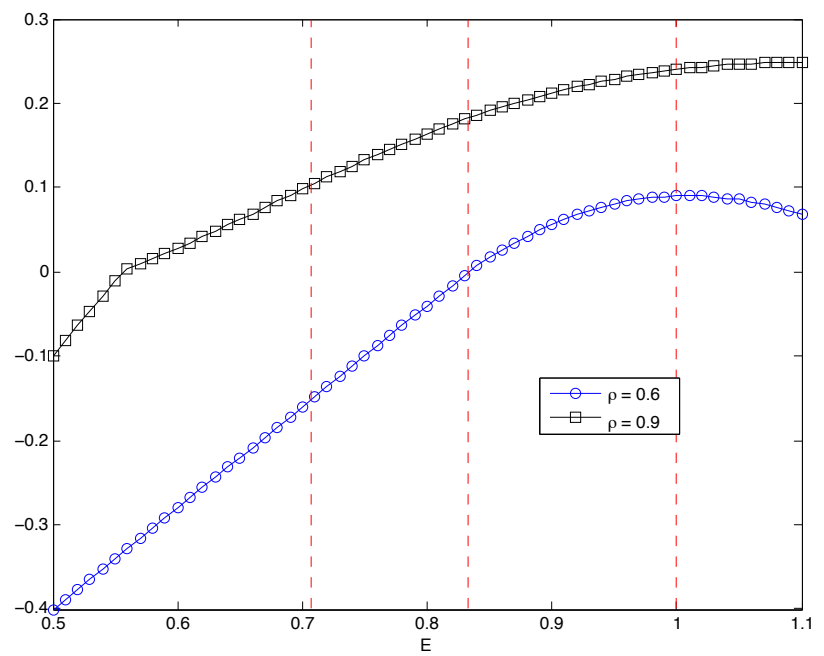

Figure 7: Numerical illustration of the HF's expected payoff vs. the manager's proposal $E \in$ $\left[E_{0} / 2, y\right]$ for two different values of $\rho\left(E_{0}=1\right.$ and $\left.l=0.1\right)$.

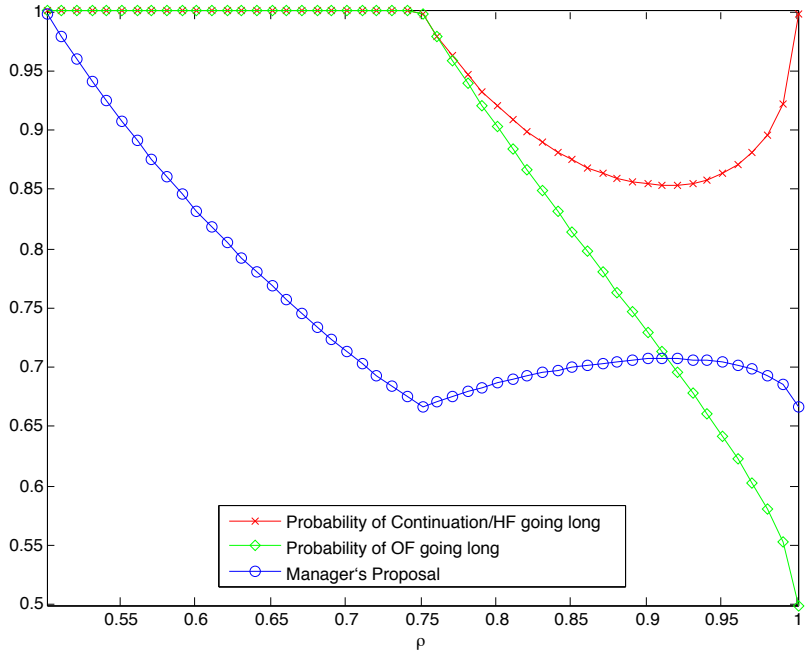

(a)

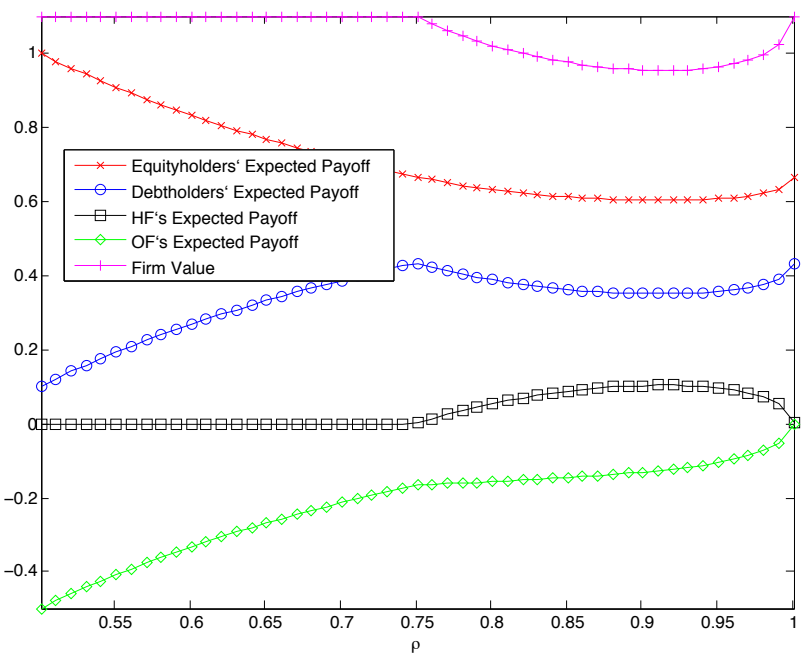

(b)

Figure 8: Numerical illustration of several equilibrium quantities vs. the OF's discount factor $\rho \in(1 / 2,1)\left(E_{0}=1\right.$ and $\left.l=0.1\right)$. In the left panel we have the manager's proposal, the probability of continuation (which is the HF's probability of going long) and the OF's probability of going. In the right panel we have the expected payoffs to the equityholders, the debtholders, the HF and the OF as well as the expected firm value. 